Journal of Jazz Studies vol. 10, no. 2, pp. 157-197 (Winter 2014-2015)

\title{
Jazz Harmony: A Progress Report
}

\section{Chris Stover}

How jazz syntax is theorized, and how it is filtered through various pedagogical frames for dissemination to increasingly sophisticated students, is evolving at an impressive rate. There is now a sizable body of literature on jazz theory and analysis, and at least three "generations" of card-carrying music theorists drawing upon and extending the rigorous work that has taken place since the 1970s, as well as carving out new epistemological ground. ${ }^{1}$ Many of these theorists are also active performing musicians, intensifying the irreducible link between jazz theory and practice, and an increasing number of nonacademic performer/composers are engaging theoretical models in a serious way, reading canonic literature, and attending scholarly conferences. The repertoire of jazz being examined has been expanded to include early jazz, various avant-garde streams, and very recent jazz. ${ }^{2}$ Besides important work validating the role of melody, harmony, voice-leading, and deep structure in tonal jazz, there have been impressive contributions in the analysis of improvisation and interaction, the latter pointing toward important connections between analysis and the vital body of seminal ethnomusicological work on interaction. ${ }^{3}$ Radicalizing this last consideration, there is important recent work on what George Lewis refers to as the Afrological aspects of jazz performance, suggesting that there is room to invent an Afrological theoretical ontology that either interprets existing theoretical tools or imagines new ones that shimmer with the resonance of Lewis's groundbreaking work. ${ }^{4}$ While

\footnotetext{
1 A robust, frequently-updated bibliography of research on jazz can be found at http://mtd.uncg.edu/ jazztheory/.

${ }^{2}$ A few examples include Benadon (2009) on early jazz; Block (1990 and 1993), Steinbeck (2008) on free jazz; and Arthurs (2011) on very recent jazz.

${ }^{3}$ Foundational works in analyzing background structures in jazz include Larson (1996 and 2009), Martin (1988, 1996, and 2012), and Strunk (1979 and 1985). Michaelsen (2013) is one of the first to closely engage interaction from an analytic perspective, drawing upon foundational work by Berliner (1994), Monson (1997), and Rinzler (2008). We should also consider Brinner (1995) in this thread; although he does not engage jazz, Brinner's work on interaction offers many valuable insights that jazz scholars might run with.

${ }^{4}$ Lewis's representation of Eurological v. Afrological is most concisely laid out in Lewis (1996). Lehman's (2012) and Steinbeck's (2008) respective studies both draw upon and extend Lewis's work. Fred Moten's (2003) work on African-American aesthetics is also resonant here. While
} 
mainstream jazz pedagogy has not yet engaged notions of interaction or anything like an Afrological ontology, and while it continues to propagate the notion that there is a canonic jazz repertoire to learn (that of the Great American Songbook), and a canonic body of exemplary works and practices to engage (the recordings of a small subset of jazz musicians from the bebop era and just beyond; very approximately 1945 through the early 1960s), there are increasingly nuanced ways to do that learning and engaging, the borders around repertoires are slowly becoming more porous, and assumptions about the centrality of bebop and post-bebop are being challenged. ${ }^{5}$

The aims of this essay are twofold. On one level, it is a careful look at three recent textbooks on jazz theory, and should be read in this light as a review. On another level, though, it extrapolates from its status as a review to consider what jazz theory (and specifically jazz theory pedagogy) is today-from this perspective it might be read fruitfully as a follow-up to Henry Martin's 1996 state-of-the-discipline paper in this journal; we are coming up on the eve of its twentieth anniversary, so a follow-up seems germane at any rate. This essay focuses on jazz theory pedagogy, but throughout I urge the reader to consider to what degree the scholarly practices that Martin described in 1996 have or have not formed a substrate for the ways of teaching and learning that have followed in the subsequent nineteen years. A number of questions will be raised, then, that transcend the contents of the volumes under consideration, asking the reader, in a few cases, to consider why this or that theoretical construct became accepted into mainstream jazz pedagogical practice (and offering some possible alternative frameworks) or why certain aspects of jazz practice have traditionally been foregrounded at the expense of others (I will do this in as value-free a way as can be mustered; asking earnest questions rather than casting judgments or taking sides). It will also make a plea for increasingly robust dialogue between analytically-oriented theory and a pedagogy that has

it hasn't yet made its way into mainstream music-theoretical discourse, Anthony Braxton's extraordinary, complex music-philosophical system (Braxton 1985) is a crucial subject for future inquiry. I believe it is imperative for jazz theorists to engage their subject matter through an Afrological lens (be it Lewis's, Braxton's, or otherwise) - this would open up increasingly rich possibilities for a real immanent critique of jazz practice (Gary Peters touches on this possibility in Peters $(2009,76-86)$; see also Stover 2013b) that works from within the syntactic and discursive positions of its practitioners to consider what kinds of possibilities might emerge, rather than foreclosing possibilities based on (potentially ill-fitting) theoretical constructs imposed from without.

${ }^{5}$ It is revealing that Derek Bailey's $(1993,53)$ concerns from over twenty years ago, about jazz pedagogy's failure to understand or engage the actual motivations of, and values held by, musicians of the bebop era, have not been addressed in pedagogical literature in any serious way at all. 
generally been, to its great credit, production-oriented. All three volumes under review are intended to contribute to courses on how to be an improvising jazz musician, and in what we'll see are considerably divergent ways orient the user toward some very specific ideas about what that means, and what are the most essential features of a modern jazz practice.

A few more contextualizing questions are in order, which should be kept in mind through the narrative that follows. First, in a theoretical methodology, what gets to count as first-order information-what is privileged, and why? How is that information structured, how is it sequenced, and what prior knowledge is assumed? Toward what end is the reader being steered, and what are the political reasons for doing so? A subtext here is that there are many entrance points to a deep investigation into the syntactic objects and processes that define jazz harmony. But a further question looms beneath the surface, which has to do with how we navigate between how a methodology reflects the practice of the exemplars that it claims to represent, versus how it aims to steer ongoing or future practice. All three texts under consideration here balance those two needs in very different ways, with fruitful results in all cases. That those balance points, and even the respective assumptions about what constitutes essential fundamental information, vary radically between the three volumes demonstrates the staggering breadth of the subject matter as well as the fact that there are still very few universally agreed-upon aspects of jazz practice or how to teach it.

The Berklee Book of Jazz Harmony (Hal Leonard, 2013), co-authored by Joe Mulholland and Tom Hojnacki, represents the most deeply-rooted of the three books from the perspective of pedagogical practice. Mulholland and Hojnacki develop a conceptual frame that has animated the music theory curriculum at the Berklee College of Music for several decades, including a hierarchically grounded analytic orientation, a robust notational system calculated to reinforce that analytic reading, and a fundamental assumption of chord-scale isography that underlies its entire theoretical orientation.

David Berkman's new volume for Sher Music Publications, The Jazz Harmony Book (2013) is perhaps the most intensely focused of the three volumes, honing in on a particular aspect of jazz practice-reharmonizationand locating it as both idiom-defining and ontologically prior. Berkman develops a personal model that describes how all harmonic actions are elaborations of a tiny pool of functional archetypes (tonic, dominant, and subdominant), which he illustrates via a nested hierarchy of concentric circles that build out from that central node of functional archetypes into five (or maybe six, we'll see) increasingly removed categories of substitutive function. 
While both the Berklee volume and Berkman's book limit their focus to harmony (some ramifications of which will be problematized below), Dariusz Terefenko's Jazz Theory: From Basic to Advanced Study (Routledge, 2014) aims for a comprehensive approach that subtends harmony, melody, voice-leading, formal design, and improvisational considerations. ${ }^{6}$ Terefenko's book, therefore, is really in a different methodological category than the other two, so direct comparisons that emerge in the following narrative should always assume that caveat. That said, an important theme will emerge below that questions the efficacy (and pedagogical value) of an approach that decouples harmony from melody, voice leading, and so on; furthermore, I will suggest that even though Mulholland and Hojnacki and Berkman are careful to remind their readers that linear considerations are important, their examples rarely speak to this in anything but the most cursory way. ${ }^{7}$

It is a happy accident that these three volumes have been released in such temporal proximity to one another, since a comparative look at them reveals much about the most important questions that animate jazz pedagogy, and by extension jazz theory today. ${ }^{8}$ In the following investigation, I will weave in a somewhat improvisatory manner through the three texts, focusing on various aspects of each, drawing lines between them, and using them as conduits to reach toward larger questions and concerns. A few main themes will emerge repeatedly in different contexts; I invite the reader to consider these as something a de facto thesis for this essay.

\section{THE BERKLEE METHOD UPDATED}

Mulholland and Hojnacki's treatment of harmonic function in The Berklee Book of Jazz Harmony is streamlined, specific, and clearly structured to orient the reader toward thinking of harmony in a very focused way. There are great pedagogical benefits to this method, as well as some conceptual limitations

\footnotetext{
${ }^{6}$ Mulholland and Hojnacki begin with an implicit indictment of pluralistic approaches (see their introduction, p. vi). Terefenko, on the other hand, offers a gentle entreaty against separating harmony from other factors (Terefenko, 332).

${ }^{7}$ For example, while Berkman asserts that "harmonizations are improved by good voiceleading in the inner voices of the chords" (33), the example that this statements follows (32) does not attend to voice-leading tendencies: if we follow the inner-voice melodic contours carefully, it becomes apparent that individual melodic strands leap from one active tone to the next with little regard for linear continuity.

${ }^{8}$ These three texts also extend a long, rich history of jazz theory pedagogy, exemplified by, among many others, Mehegan (1959), Haerle (1982), Jaffe (1983), Levine (1995), and Reeves (2006).
} 
that will emerge in the following narrative. The theoretical thrust of the book extends from four fundamental concepts: the primacy of functional categories (tonic, "subdominant," and dominant; p. 3-8), diatonic root movement (with motions by second, third, and fifth; pp. 9-13), a careful consideration of harmonic rhythm (13-19), and chord-scale isography (with some ontological priority given to scales). ${ }^{9}$ All chromatic activity, all formal design, and most improvisational considerations extend from these conceptual themes. ${ }^{10}$

Some of the sequencing in Mulholland and Hojnacki's book is unusual and perhaps even controversial. One unusual feature of its presentation is the introduction of secondary dominants long before any notion of tonicization has been established-long before the reader has a conception of what an applied dominant-to-tonic relation means. They justify their methodology by introducing secondary dominants not as tonicizing intensifications that prolong their target chords, but as chromatic intensifications of diatonic functions. That is, an A7 chord moving to $\mathrm{D}$ minor in the key of $\mathrm{C}$ is considered initially not as tonicizing ii, but as a chromatic alteration of vi, intensifying the move to its target chord without embuing the latter with any local tonic identity. This is a valuable way to think of chromaticism in monotonal contexts; after all, when we arrive on that ii chord, it is still ii by most metrics, not a digression to a subordinate key of $\mathrm{D}$ minor, however brief. Mulholland and Hojnacki suggest as much: upon resolution of the applied dominant chord, they describe how "the sense of relief associated with the normal resolution of a secondary dominant only reaffirms the original key identity" (39). ${ }^{11}$ But of course there is still a dependent, teleological component to this motion. ${ }^{12}$ Mulholland and Hojnacki engage the goal-orientation of

\footnotetext{
${ }^{9}$ Chord-scale theory is first introduced on pp. $\mathrm{x}-\mathrm{xi}$, and is woven into much of the subsequent text.

${ }^{10}$ In a brief aside (p. 8), Mulholland and Hojnacki describe a "basic expressive grammar" through four functions of scale degree tendencies: "progression (forward motion)," "prolongation (color variation within a functional group)," "retrogression (retreat from tension)," and "resolution (release of tension)." In other words, they assert that scale degrees have different kinds of expressive proclivities (not always exactly correctly: they describe $\hat{4}$ as the defining tone for the subdominant category because of its tendency to resolve to $\hat{3}$, which is almost never how it behaves in that context, but that is a rare overreach for them). It is a pity that they do not develop these concepts further, as their way of describing these actions is elegant and compelling.

${ }^{11}$ But note on the following page they describe how altering a diatonic chord to become an applied dominant "destabilizes the harmony"-I would like to think of this seemingcontradiction not as an irreconcilable aporia but as an enriching multiple interpretation.

${ }^{12}$ Terefenko uses the phrase "prolongation by arrival" to describe similar harmonic actions. This conception derives from one of Henry Martin's important syntactic claims about tonal
} 
applied V chords through their graphic notation. A curved arrow shows the drive of the applied dominant to its target tonic (pp. 40-41), and then square brackets link a dependent ii to that $\mathrm{V}$ (51-56). ${ }^{13}$ Two crucial pieces of information are revealed in this notation: that the move from ii to $V$ is different in kind from that of $\mathrm{V}$ to $\mathrm{I}$, and that ii- $\mathrm{V}$ can be conceived as single second-order syntactic object with its own internal motion. ${ }^{14}$ That is, "the bracket identifies the chords as a functional pair" (51), whereas "the arrows show not simply progression, but resolution to the expected target" (47). The implications of thinking of $\mathrm{ii}-\mathrm{V}$ as a single syntactic object have not yet been adequately theorized in jazz, and are contradicted in some important ways by chord-scale narratives. But this ties into one of the most impressive parts of Mulholland and Hojnacki's book: its extensive treatment of harmonic rhythm. Harmonic rhythm is often overlooked in introductory texts, and is an aspect of jazz composition and reharmonization that is often incompletely understood by students. One of the most important points that Mulholland and Hojnacki make has to do with the metric implications of the ii- $\mathrm{V}$ syntactic unit. While they don't use this exact language, they clearly suggest that the internal motion of ii $-\mathrm{V}$ as it progresses to $\mathrm{I}$ is a hierarchy of tonal impulses; the directed motion of $\mathrm{V}$ going to $\mathrm{I}$ is the strongest and most significant action, abetted by the strong-beat arrival of tonic, and the ii functions as an appoggiatura embellishing $V$ (this is easy to hear if we attend to the guide-tone motion), and like an appoggiatura is most effective as a strong-beat phenomenon. ${ }^{15}$ Mulholland and Hojnacki treat this very thoroughly, and even engage anomalies like tunes that start with applied dominant chords and chains of "extended dominants" (49) like the bridge to "I Got Rhythm." They miss an

jazz (Martin 1988, 12-15), and while neither is specifically describing the local motion of an applied dominant chord to its target tonic, the principle is very much germane here.

${ }^{13}$ There is an implication here, by the way, that ii is the fundamental pre-dominantfunctioning chord in jazz - this is not a controversial assertion, but one which we will see varies from some other accounts, including that of Berkman's initial exposition of functional categories. I will suggest below that ii should be considered as the base-level pre-dominant chord in tonal jazz, with IV as common substitution.

${ }^{14}$ Throughout this essay I will use this consistent orthography for a pre-dominant-functioning chord built on the (global or local) supertonic and dominant-functioning chord built on the (global or local) dominant. This is in the interest of maximum clarity when discussing ii- $\mathrm{V}$ as a single syntactic unit with internal motion, and will hold whether or not there are extensions beyond the seventh in either or both chords, and whether the ii is actually a iiø7 as is most often found in minor keys. See Strunk $(1979,6)$ for a similar rationale regarding clarity of graphic notation v. specific details of pitch content.

${ }^{15}$ Terefenko hints at this as well; best illustrated in his Figure 13.7 (p. 157), which casts ii-V as a diminution. 
opportunity to score a small analytic point when they suggest that applied dominant chords, "with the exception of the V7/V, typically appear on weak harmonic stresses" (49). Those strong-beat V/Vs might be better construed as intensifications of pre-dominant harmony, that can then move to a dominant ii- $\mathrm{V}$ unit on a comparatively weaker beat (the ii in this case acting in its appoggiatura role as described above), as we see in the first bars of Gershwin's "But Not For Me" (Fig. 1). This is an elegant solution to the tricky analytic task of accounting for a retrogressive progression from more to less dissonant $(\mathrm{V} / \mathrm{V}$ to ii) that occurs in various forms in many tunes in the standard jazz repertoire.

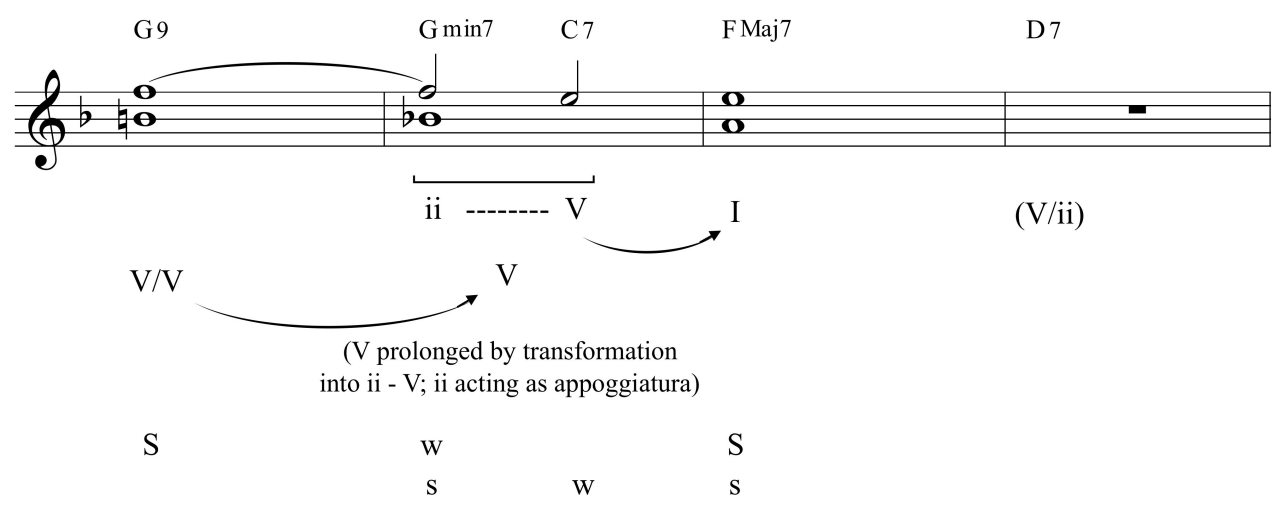

Figure 1. "But Not For Me," mm. 1-4.

Where Mulholland and Hojnacki's graphic notation, and the concepts that it embodies, falls short is in describing dual functions, which are everywhere in tonal jazz. To take one example, consider this brief passage from Antonio Carlos Jobim's "Desafinado" (Fig. 2). The Gmin7 chord in $\mathrm{m} .9$ is a ii chord, approached by its own ii- $\mathrm{V}$, pointing back toward the home key and intending a (virtual) $\mathrm{V}$ chord to follow, but it also functions as the iv of a iv(actual) $\mathrm{V}$ in $\mathrm{D}$ minor (which turns out to move to $\mathrm{D}$ major, but that is another question altogether ${ }^{16}$ ). What is important here is that it is not ii or iv, it is both, and essentially so; its dual identity is part of the particular temporal and harmonic narrative that plays out as the song unfolds.

\footnotetext{
${ }^{16}$ I describe the implications of this surprising D major resolution, as well as other aspects of "Desafinado"'s harmonic progression, in Stover (2015).
} 

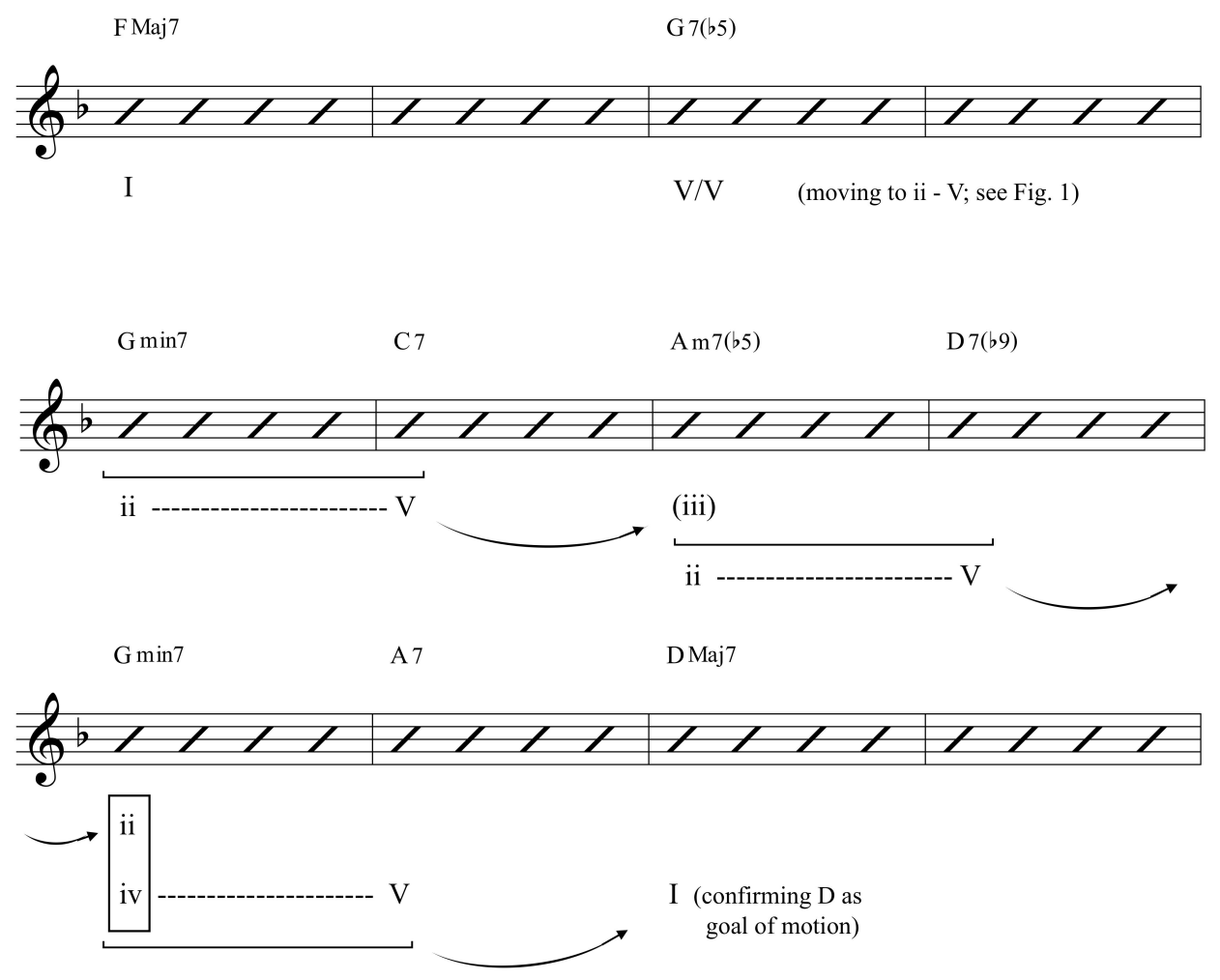

Figure 2. "Desafinado," mm. 1-12.

For another example, consider the well-known string of ii-Vs beginning in m. 2 of Charlie Parker's "Blues for Alice," which are generated backwards from a IV7 arrival in m. 5 (Fig. 3). ${ }^{17}$ The way that Mulholland and Hojnacki describe applied ii-Vs as elaborations of diatonic functions (see their Fig. 2.37, p. 52) accounts elegantly for Parker's use of Eø7 for the first ii but Dmin7 and Cmin7 for the next two; Eø7 and Dmin7 function dually as diatonic chords in $\mathrm{F}$ and as local actions that engender their respective Vs, irrespective of the qualities of the resulting Is. In this sense, the initial move from I to viiø7 is a diatonic motion (an away-from gesture) that then is recast as the ii of a ii- $\mathrm{V}$

\footnotetext{
${ }^{17}$ Throughout this essay I will use a consistent hybrid notational system to describe chord function: diatonic chords will be indicated by scale degree and chord quality (I, ii, iii, etc.), and sevenths will follow lead sheet convention (Maj7, $\min 7,7, \varnothing 7$, o7). Occasionally, when the chord quality is of lesser importance, I will simply use the Roman numeral (as in "ii-V-I"; see also fn 14 above). While this goes against Strunk's (1979) convincing appeal for a notational system that locates Roman numerals and lead sheet symbols as separate categories with their own internal logics, I believe that for the purposes of the analytic points I am making here it is more useful to conflate them.
} 
in $\mathrm{D}$ minor, enacting a moving-toward gesture that turns out to spin sequentially toward the $\mathrm{B} b 7$ arrival in $\mathrm{m}$. 5 . The diatonic reading models our temporal experience of hearing the progression, while the latter models its compositional derivation. The Dmin7 in $\mathrm{m} .3$ also holds a dual function as a diatonic arrival and as a continuation of the moving-toward impetus enacted by the previous ii- $\mathrm{V}$. When we arrive at the Cmin7 chord in $\mathrm{m}$. 4, however, we begin a harmonic motion that is clearly focused on a single task, intensifying the move to IV to begin the next phrase. Somewhere around this point, then, we can retroactively consider the entire sequential passage starting in $\mathrm{m} .2$ as a prolongation of that intensification, reinforcing the concept of prolongation by arrival that Martin has described as an essential characteristic of tonal jazz (see fn 12 above).

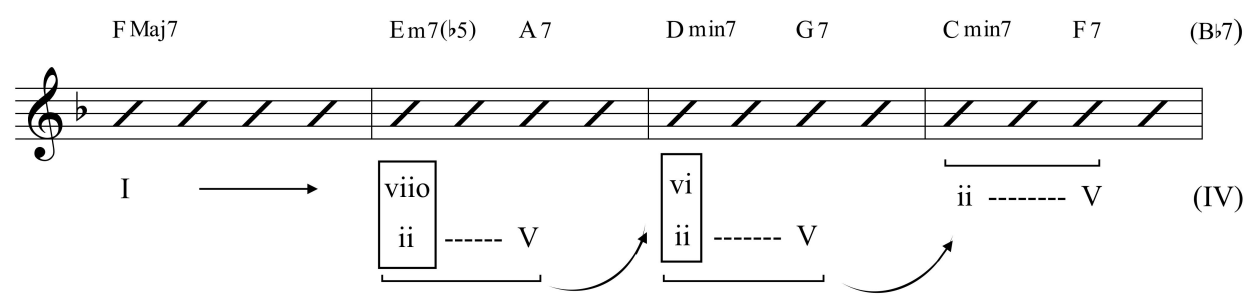

Figure 3. Dual-function reading of "Blues for Alice," mm. 1-5.

There is a great deal of valuable information for improvising musicians encoded in the adjectives I have chosen to describe these motions. An awayfrom move from stable tonic to a functionally ambiguous viiø7 chord provides the improviser opportunities to consider how to craft a melodic utterance that resonates gesturally with that impetus, increasing tension by emphasizing more unstable melodic tones. ${ }^{18} \mathrm{~A}$ moving-toward gesture assumes an entirely different kind of kinetic energy, which could be channeled as early as m. 2 through the affective implications and resolution-drive of those unstable tones, pointing toward its ultimate arrival in a new harmonic space in $\mathrm{m}$. 5. This transcends chord-scale considerations to take into account ebbs and flows of affective forces, and points toward a way of reading improvisation in tonal jazz that takes into account the countless examples of personalized improvisational syntax that chord-scale theory does not adequately explain. ${ }^{19}$ In a promising

\footnotetext{
${ }^{18}$ See below for a comparative look at how viiø7 is treated in these three texts.

${ }^{19}$ Just from a historical perspective, we could look at improvisers like Thelonious Monk, Sonny Rollins, Warne Marsh, Booker Little, Andrew Hill, Jackie McLean, Miles Davis, Herbie Hancock, Joe Henderson, and many, many more-not to mention earlier and later
} 
turn, Mulholland and Hojnacki do eventually touch on the possibility of syntactic pluralities, urging the reader to "[m]ake peace with this ambiguity! It will help you ask the right questions about context and expectation" (103), but they suggest that there is a single context-determinate solution, stopping short of suggesting the real coexistence of multiple syntactic trajectories.

Another important theme that Mulholland and Hojnacki take on is the role that modes play in contemporary jazz. There are three ways in which modes are evoked in Mulholland and Hojnacki's methodology. The first is the mode as a constituent part of a chord-scale, more or less irreducible from an extended chord. ${ }^{20}$ The second is the color shifts that occur through modal interchange, which Mulholland and Hojnacki extrapolate from basic major/minor mode mixture to consider parallel relations between a variety of diatonic modes. ${ }^{21}$ Mulholland and Hojnacki's introduction to modal interchange chords follows standard practice of incorporating chords from minor into the parallel major key, beginning with chords that involve the expressive b6 (iv7, iiø7, bVI7-curiously, they do not consider viio7 just yet ${ }^{22}$ ) and then continuing with bVII7, v7, and a few others, including chords like IV7 (derived from the parallel Dorian mode) and bIIMaj7 (from the parallel Phrygian mode). While they are far from alone in suggesting that modal interchange is typically a major-key phenomenon, since "minor keys already have a rich chord vocabulary due their multiple modal sources" (131), it seems we could find value in considering melodic and harmonic minor as examples of modal interchange as well: major impinging on minor for expressive harmonic purposes.

Their third explication of modal practice is an entry into purely modal spaces, following certain strands of jazz practice since the mid-1960s. When

improvising musicians - as exemplary soloists that challenge the notion that chord-scale readings adequately describe even mainstream jazz practice, but about whose improvisational practice we might fruitfully apply a theory of ebbs and flows of directed energies such as this narrative suggests.

${ }^{20}$ This is a reductive description: in reality Mulholland and Hojnacki are extraordinarily careful to make contextually-grounded distinctions between basic chord tones, tensions (both of which map unproblematically onto scales or modes), and "avoid" notes (which don't map in quite the same way). I will return to chord-scale considerations below.

${ }^{21}$ Compare this to Berkman's version of modal interchange below.

${ }^{22}$ Another curiosity: when they do introduce viio7 (as a dominant-functioning chord in minor), they assert that "it is not used commonly as an alternative to V7" (96). I find this puzzling; while dominant-function viio7 chords may be comparatively rare (but not unheard-of) in the fakebook versions of jazz tunes, they abound in the original versions of many of those tunes, and an inclusive theory of jazz harmony should not foreclose their possible use from the perspectives of composition, improvisation, or reharmonization. 
they move away from modes as constituent parts of chord-scales and into an investigation of modes as stand-alone syntactic spaces, Mulholland and Hojnacki's treatment of modality gets somewhat subjective, if not proscriptive. They offer a number of "standard harmonic phrases" (p. 188ff) for various modes, but it is not clear what makes these standard or how they affirm a particular modal space. This strikes me as somewhat capricious: claims are being made about mode-affirming progressions with little explanation or evidence for why or how they affirm those modes. Claims are also made about characteristic voicings with no indication of their provenance (c.f. the suggestion that in the Phrygian mode "the tonic chord is often voiced as I7sus4(b2)" (195). Or assertions about usable or unusable chords in different modal spaces; e.g. a curious claim that iiø7 is foreign to Aeolian because "the diminished fifth above the root is inconsistent with the perfect fifth chord structure that is associated with modal music" (194). Associated according to whom? Mulholland and Hojnacki's claims about modal harmony should be supported with detailed musical examples; otherwise they are simply suggestions based on the authors' taste. Now it must be said that Mulholland and Hojnacki's treatment of modal harmony is in line with contemporaneous pedagogy: even the best accounts of modal practice in jazz do little more than offer lists of traits that might signal "modal" (see Miller 2000 and Waters 2011 for two particularly thorough accounts, but which still seem content to enumerate a few modal indices with no real systematic consideration of how they might behave or interact $\left.{ }^{23}\right)$. The point here is not to indict any of these accounts, but to reinforce the fact that modal jazz remains virtually untheorized, despite a few preliminary steps toward some kind of rigorous conceptualization. Or in positive terms: modal theory for jazz remains a wideopen field, awaiting further exploration. Is there a way that we might take Mulholland and Hojnacki's treatment of modality as a means to open a broader conversation about modal usage in post-bop jazz and consider from a discipline-wide perspective how we might theorize it more rigorously? For example, Mulholland and Hojnacki ask why, in modal spaces, we do not consider a rich array of substitute functions, chromatic inflections, and so on like we do in tonal spaces, to which they offer: "no substitute is needed: the sound of the mode itself is intrinsically satisfying" (184). This is a disappointing response, and implies that perhaps tonality is not intrinsically satisfying if it needs all of those variations and extrapolations. A better argument would be to point to the relative unexploredness of modal spaces in

${ }^{23}$ Mulholland and Hojnacki's list of modal traits (183) is based on these, as is Terefenko's (91, fn 5), which cites Waters. 
jazz contexts: there is still a great deal of room for compositional and improvisational creativity within single extended modal spaces. We should also note that simple diatonic tonal function is alive and well, and many young jazz musicians are becoming increasingly attracted to the possibilities afforded by diatonic harmony, triadic structures, chord inversions, and more open textures.

In spite of the focused concerns laid out here, and bracketing my healthy suspicion of any assertion of chord-scale equivalence (as well as my suspicion of an approach that compartmentalizes aspects of musical syntax like harmony), I find a great deal to admire in Mulholland and Hojnacki's book. Their systematic approach greatly simplifies an endlessly complex and creative syntactic terrain (while occasionally foreclosing some creative possibilities), but it also leaves enough doors open for the student to pursue other lines of flight and to imagine new syntactic spaces.

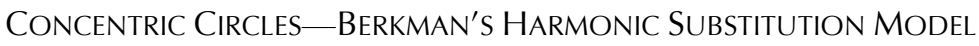

To an even greater degree than Mulholland and Hojnacki, David Berkman focuses on harmonic aspects of jazz practice. Central to his methodology is a model that will resonate for both Schenker-inspired jazz theorists ${ }^{24}$ and for those that might wish to consider a recasting of Rameau's conception of harmonic function. ${ }^{25}$ Berkman begins by describing three functional categories - tonic, subdominant, and dominant-which he associates with I, IV, and $\mathrm{V}$ respectively (1). He then builds a series of concentric circles out from this central core, starting with diatonic substitutions (13-17; these include iii7 and vi7 for tonic; ii7 for subdominant; viiø7 for dominant ${ }^{26}$; importantly, he locates seventh chords right away as first-order syntactic objects, in line with most modern thought), then secondary dominants and their related ii7 chords (19-20), then "passing chords" (40-50, and about

\footnotetext{
${ }^{24}$ Note, though, that Berkman's method resonates with Schenkerian theories only to the extent that considers harmonic substitutions as elaborations and sometimes diminutions of fundamental structures; it is interesting to consider what would happen if Berkman's model was taken in a more rigorous analytic direction. There is one significant barrier to this possibility, which is that Berkman's circles don't really represent the nested hierarchies that they appear to model. That is, the fourth circle does not depend on the third circle for its functional derivation, nor does the fifth depend on the fourth. The model could more accurately have been drawn as a central node with radiating branches that are also themselves linked; a semi-rhizomatic model (or a rhizomatic model with a single arborescent bundle that generates a multiplicity of possible connections).

${ }^{25}$ See below; I am actually very intrigued by what a "neo-Ramellian" reading might reveal.

${ }^{26}$ Note that Mulholland and Hojnacki insist that viiø7 is not a viable dominant-functioning chord (Mulholland and Hojnacki, 8).
} 
which below), then "modal interchange chords" (51-66), and finally tritone substitutions (67-83). A graphic illustration of the five circles is given on p. 67. The idea of moving through these circles, and in doing so relating increasingly distant harmonic objects to basic functions via easily traceable transformational paths is highly compelling. That the mappings, especially in the outer circles, don't quite work out in the way that Berkman suggests is problematic as a theoretical model, but not as a pedagogical frame that aims to locate chromatic actions in relation to diatonic ones, thereby easing the student's entry into more complex harmonic situations. The critique that follows will not focus on the transformational or generative soundness of the model, but will instead focus on a few analytic claims (or, more accurately, claims of analytic provenance) that result from how certain terms are defined in the model, and how the model occasionally forces the reader into a particular way of engaging a harmonic action that is not necessarily in line either with how that action locates in its larger harmonic context or with how it is experienced.

First, though, a few words on the term "subdominant" (also, of course, the term that Mulholland and Hojnacki use) and on definitions of cadences. While a close engagement with how Rameau's functional categories might or might not be a useful point of departure for theorizing jazz practice is far beyond the scope of this paper, it is important to acknowledge the generally unacknowledged residue of Rameau's subdominant function in jazz theoretical discourse. Many jazz texts use "subdominant" rather than the more accepted (in contemporary usage) "pre-dominant" label; a few (including Terefenko, below) use the latter, but nowhere is there a serious consideration of why one functional label is better than another, or exactly why we should orient in one direction or the other.

One reason that "pre-dominant" is a better term for the kinds of harmonic phenomena under discussion is because in jazz, IV has a second, equally significant harmonic function, owing in no small part to its structural role in blues and African-American spirituals. By focusing on the ii of a ii-V as a pre-dominant entity (and, as we have started to consider above, as a constituent part of a larger syntactic object), we can save the subdominant function to describe the many situations where IV moves to I (or otherwise prolongs tonic). This is in line with Rameau's conception. As Thomas Christensen has described, Rameau characterized both subdominant and dominant as "drawn toward a central tonic by a kind of gravitational pull" (2004, 131); this centricity is of course very much in line with Berkman's concentric-circle model. Mulholland and Hojnacki touch on this briefly in their roster of cadence types (p. 19), although they stick to their guns by continuing to use "subdominant" to describe the ii of a ii-V; this is a missed 
opportunity to tease out an important functional distinction. An argument for ii as the pre-dominant prototype in jazz might begin with its role as instigator of circle-of-fifth motion (keeping in mind that that motion is actually generated by the end-directedness of I) and with the guide-tone motion that abets its dependent relation to $\mathrm{V}$. IV, then, could be considered a next-circle diatonic substitution for ii, à la Berkman's model but reversing the hierarchical flow. The centuries of arguments in Western theoretical literature about the relationship between ii7 and IV(add6) does not seem particularly relevant here, since the latter so rarely appears in jazz syntax, although we should make clear that this means jazz syntax as practiced by jazz musicians, not as the harmonic syntax of the Great American Songbook from which so many jazz tunes derive.

Berkman defines cadences as "harmonic phrases, the 'sentences' that music is written in" (1), and he likens them, metaphorically, to actual sentence constructions with nouns and verbs and so on. So the syntactically closed progression $\mathrm{I}-\mathrm{IV}-\mathrm{V}-\mathrm{I}$ is a cadence (2), as, it seems, is any short chord progression, as evidenced in a brief analysis of Bach's setting of "Aus meines Herzens Grunde" (14-15), where I-V-vi and then IV-V-I are both described as cadences, with no consideration of their contextual role in supporting a motion to a phrase-ending $\mathrm{V}$ in $\mathrm{m} .4{ }^{27}$ Berkman's definition is more appropriately given to what Mulholland and Hojnacki call "harmonic phrases," whereas a cadence in jazz is better defined via Rameau's conception once again, as "a structural closing, one defined by the scale degree upon which the bass voice end[s] or the interval by which the bass voice moves" (Christensen 2004, 113). Mulholland and Hojnacki define cadence as "a recognizable accumulation or release of harmonic tension at the end of the phrase" (Mulholland and Hojnacki, 19), which is more in line with Rameau's definition, and with most conventional readings. ${ }^{28}$ Berkman's definition of cadence is not only too liberal, it is inaccurate in the sense that it ascribes cadential function to short syntactic progressions regardless of their metric location or their role in composing out a musical phrase.

The inner circles of Berkman's model (the functional archetypes themselves, diatonic substitutions, and applied $\mathrm{Vs}_{\mathrm{s}}$ and $\mathrm{ii}-\mathrm{Vs}$ ) are clear and convincing.

\footnotetext{
${ }^{27} \mathrm{NB}$ marked as m. 5 in the example and supporting narrative, as the anacrusis is given as m. 1 . ${ }^{28}$ Some of Mulholland and Hojnacki's analyses misattribute cadential function, however. See, for instance, their Figure 2.36 (p. 52), where a m. 4 V7/IV is labeled as half cadence (and by extension as a phrase boundary), when in reality it points toward a m. 5 arrival on its target IV chord. Similarly, in Figure 4.73 (p. 113), half-cadential status is given to the dominant chord in $\mathrm{m} .16$, when in fact it points to the next phrase beginning; in other words $\mathrm{m} .16$ is not an arrival; it is an anacrusis (by elision).
} 
His explanation of shared diatonic function via common tone (IVMaj7 and iimin7 sharing $\hat{4}, \hat{6}$, and $\hat{\imath}$, for example), and his framing of secondary dominant function as an extrapolation of diatonic function (and, as with Mulholland and Hojnacki, of the second-level syntactic connectedness of the applied ii to its $V$ ) is uncontroversial. The outer circles, however, pose a few problems.

Berkman's definition of passing chords (40) will raise some eyebrows. Most significantly, his passing chords do not pass-they act as upper or lower neighbors to their target chords (usually), as diatonic or chromatic embellishments. This is more than a trival taxonomic concern. The gesture of passing is one of the more powerful actions in tonal music; as Joseph Dubiel describes, it is fundamental to Schenker's entire concept of prolongation of fundamental events. When a consonant chord is used to harmonize a dissonant passing tone, it

takes on the passing nature of the tone, and retains it even under subsequent transformations...; indeed 'Schenker's theory' as we know it can be construed as an enormous extension of just this claim. Schenker can use the passing tone as the basis for his entire model of musical coherence precisely because he believes that the effect of 'being passed' can never be drowned out... ${ }^{29}$

An extrapolation of the passing gesture is what animates Strunk's thirds-aspassing-chords in his analysis of "Stella by Starlight" (Strunk 1979), and it resonates with Coltrane's thirds-as-steps implicit in the title of "Giant Steps." Berkman's passing chords do not share this characteristic, and are better described as neighbor or embellishing chords. Why this is a bigger deal than the simple replacement of one technical term for another is that passing chords (and other passing phenomena) are terribly important to foreground jazz syntax; this point is lost in Berkman's narrative. ${ }^{30}$

${ }^{29}$ Dubiel (1990, 317). Dubiel goes on to describe some "negative examples" from Schenker's Counterpoint that reinforce my critique here: "examples of dissonance approached or left by skip, but what they are meant to exemplify is not at all what might be expected: not, that is, other-than-passing configurations in which dissonance might occur, but other-than-stepwise configurations to which the character of 'passing' might be attributed..." (320). Berkman, likewise, is not describing other-than-passing configurations as such, but as curious attributions of passing-character to other kinds of gestures.

${ }^{30}$ See Larson (2009) and Martin (1996) for examples of two methodological orientations (both with overt Schenkerian derivations) that make crucial analytic claims about both short- and long-range passing phenomena. Berkman does describe another important use of passing chords in an excellent unit on bebop harmony, the major bebop scale (or just "the bebop scale," depending on one's methodological orientation), and the rigorous methodology codified by 
In Berkman's next circle, the important notion of modal interchange is introduced. The term "modal interchange" came into common parlance in jazz practice through earlier incarnations of the Berklee methodology (clearly traceable in Mulholland and Hojnacki's text), and has become an extraordinarily valuable concept that extends major/minor mode mixture into a number of modal spaces. Modal interchange, therefore, describes the subtension and eventual blurring of tonal major and minor spaces in nineteenth-century practice and also the ways in which modes shift over pedals in tunes like in Carla Bley's "Vashkar" and Bill Evans's "Re: Person I Knew." Between these extremes is a vast terrain in which, say, a primarily tonal space is inflected modally: Aeolian impinging on tonal minor, or Lydian coloring a tonal major, for example.

Berkman's definition of modal interchange is on one hand promisingly liberal-basically any chord derived from any parallel scale-but also frustratingly dismissive of theoretical rigor, and occasionally invokes modal interchange to account for harmonic relations that might best be analyzed in other ways. This last point is illustrated through the way that Berkman describes how II7, bVII7, and \#ivø7 are incorporated into major keys. Berkman describes II7 (as it is found in tunes like "Take the A Train," "Exactly Like You," and many others, stepping up from a two-bar tonic and giving way two bars later to a ii-V) as a chord that "just sits there, without any desire to move on to the next chord" (53). Both Mulholland and Hojnacki and Terefenko offer much more nuanced explanations for the derivation of this chord; the former in particular use it to validate reading ii $-\mathrm{V}$ as a single syntactic object, in this case approached by an applied $\mathrm{V} / \mathrm{V}$ as a pre-dominant substitution, as Figure 4 shows. ${ }^{31}$

Barry Harris (Berkman, 90-106). Berkman's is by far the closest engagement with Harris's methodology of the three books currently under consideration, even when he admits that his is an extrapolation from rather than a direct re-presentation of Harris's work.

${ }^{31}$ Mulholland and Hojnacki's graphic notation handles these sorts of situations particularly well. See, for instance, their Figure 3.32 (p. 75), where the ii-V Emin7 to A7 that opens Benny Golson's "Stablemates" is analyzed as a SubV (with its related ii) of the V (Ab7) of m. 2 (which in turn is prolonged by its own related ii). 


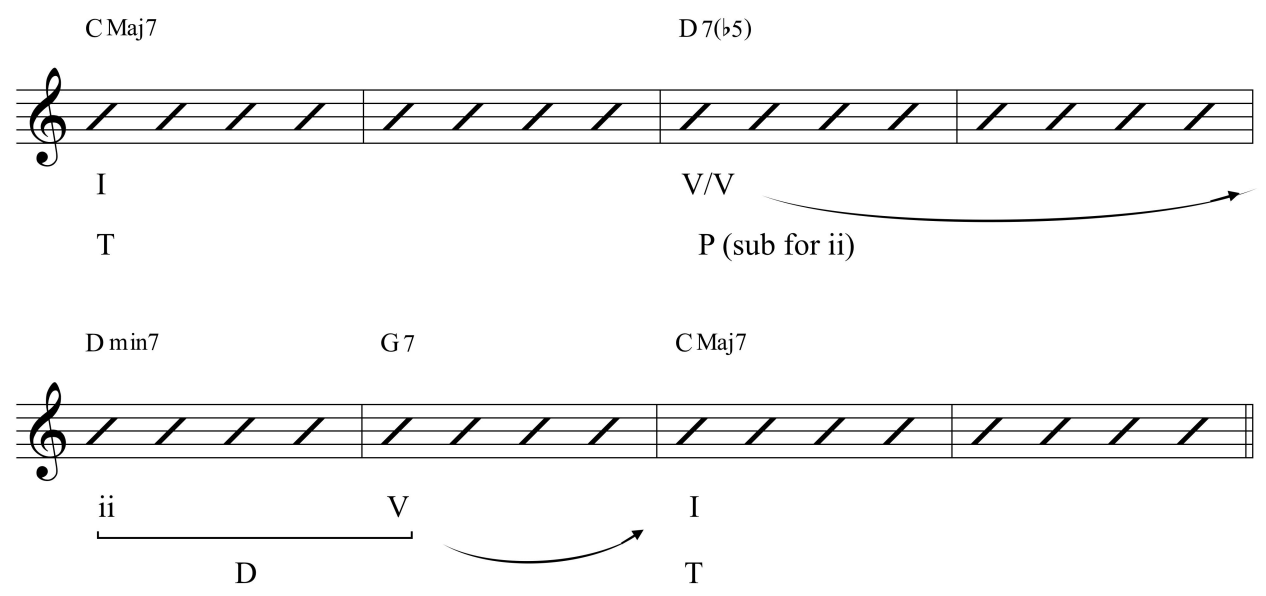

Figure 4. "Take the A Train," V/V applied to a ii-V "chunk."

The D7 chord does much more than "just sit there"-it is a integral part of the teleological motion of the phrase. The melody of "Take the A Train" only reinforces this reading, composing out a middleground rising chromatic line from $\hat{s}$ to $\# \hat{s}$ to $\hat{b}$.

Another chord given modal interchange status is bVII7. For Berkman, bVII7 to I "feels something like a plagal cadence" (64), and while he describes it as a modal interchange chord he neglects to mention which mode it derives from. Mulholland and Hojnacki similarly describe bVII7 as a "modal interchange chord from the parallel minor key" (71), mention its sonic similarity to IVadd6, and later suggest that "[ $\mathrm{t}] \mathrm{he}$ effect is more that of an elaborated subdominant minor cadence than a dominant one" (97). ${ }^{32}$ The problem with

\footnotetext{
${ }^{32}$ In this second engagement Mulholland and Hojnacki assert an Aeolian derivation for bVII7. Still later (123) they suggest that even though it seems to have a subdominant minor function, it actually has a "dominant quality," although they try to deny it true dominant function since it lacks a leading tone. This seems to me to be bending reality to fit a theoretical a priori: there are other instances of dominant-functioning chords that lack leading tones (viz. so called "minor dominants" in earlier tonal practice-see a recent exchange on minor dominants in tonal music spearheaded by Jonathan Dunsby (Dunsby et al. 2014)) and indeed Mulholland and Hojnacki go on to describe what is sometimes colloquially called a "back-door dominant" (124); bVII7 resolving directly to I in a clearly cadential manner (see also Terefenko, 138). A small analytic aside on Charlie Parker's "Yardbird Suite" (p. 237) calls attention to the misguidedness of modal interchange ascription: here Mulholland and Hojnacki describe two $\mathrm{Bb} 7$ chords as products of modal interchange, where a more sensitive reading might look at the first chord as a dominant substitution with its own related ii (see Figure 5 below), while the second is a tritone substitution for $\mathrm{V}$ of vi.
} 
these modal interchange models is that they derive what is nearly always a dominant-functioning chord from a pre-dominant prototype. Countless tunes use a variant of the progression shown in Figure 5, where an arrival on IV gives way (through simple modal interchange or mode mixture) to iv, which is then reinterpreted as the ii of a ii- $\mathrm{V}$, which then resolves up by step to the original tonic.

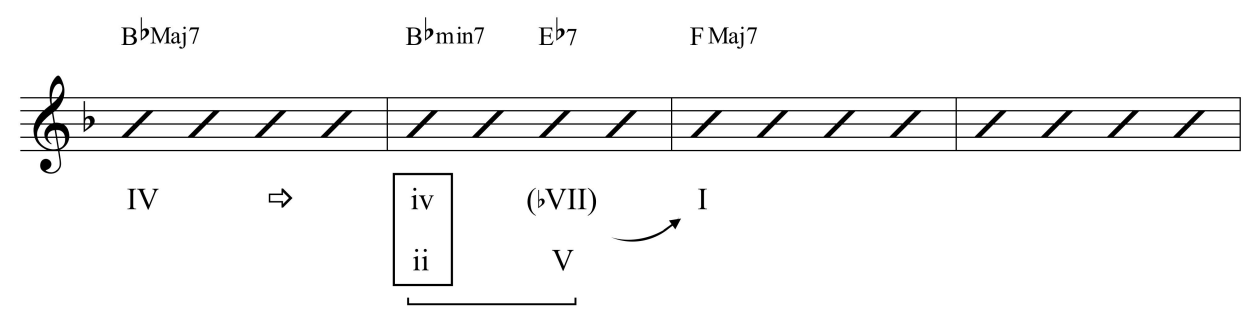

Figure 5. A dominant-functioning bVII7 moving to I.

That bVII7 clearly is functioning as a dominant substitution, with dual dominant function in the local key (as $\mathrm{V}$ of the ii-V) and in the home key (as pushing toward its tonic arrival, and it is a pervasive progression in tonal jazz. ${ }^{33}$ There are theories that locate bVII7 as a substitution for V7 (c.f. Martin 1980), but these are not considered by either Berkman or Mulholland and Hojnacki. ${ }^{34}$ There are also examples of bVII that might be described as subdominant substitutions (in "Killer Joe," or as Nicole Biamonte (2011) has described as a "double plagal" function, in many rock songs), but these are not generally situations that require thinking in terms of multiple modes, and hence of interchanges between them.

Berkman also describes the first chord of "Stella by Starlight" and "I Thought About You," \#ivø7, in terms of modal interchange (61-2). Again, it is not clear what mode he is invoking, nor why he should do so since in both cases there is an extraordinarily clear diatonic derivation for these chords (compare Berkman's reading of "Stella" to Strunk's (1979) analysis, or to

\footnotetext{
${ }^{33}$ The progression in Figure 5 is taken from mm. 9-12 of "But Not For Me," but there are hundreds of other tunes that I could have cited instead.

${ }^{34}$ An important caveat: Martin now leans toward the plagal reading of bVII7 to I, suggesting that bVII7 is "centralizing I...without using it as a dominant," and appealing to the fact that it models a move from the flat side of the circle of fifths, like IV to I, rather than the sharp side, like $\mathrm{V}$ to I (personal email exchange). I find this argument very persuasive-much more than any other explanations I've come across-but I still feel that the dual dominant reading holds an explanatory power that trumps more descriptive modal justifications.
} 
Terefenko's, for two examples ${ }^{35}$ ). This starts to suggest that we can think of just about any chromatic chords as modal interchange chords. If this is true then the value of thinking in terms of modal interchange- of the very particular expressive shift that happen when we strangely change from major to minor-loses much of its expressive potential. If we are asserting that, for example, the \#ivø7-VII7 in bar 2 of "I Remember You" (another tune that Berkman mentions) is generated via modal interchange, what mode is it articulating, and for what kinds of expressive reasons is it doing so?

The outermost circle introduces tritone substitution. Berkman offers valuable suggestions for how to incorporate variations on tritone substitution based on cues from the structure of the music. He also does a fine job of bringing different variants of tritone substitutions together with earlier reharmonization concepts like secondary dominants and modal interchange.

The second half of Berkman's book could be thought of as a sixth concentric circle (a possibility that Berkman alludes to on p. 122), extending the overarching concept of reharmonization away from tonal function (through harmonic substitution) and into what is often referred to in jazz practice as "non-functional" harmony. Berkman's is one of the more productive entries into this complex topic that I have seen (although I wish he hadn't approached in such a piano-centric way). He offers eleven categories of non-functional harmonic objects (123) - he refers to these as "organizing principles" but in most cases their manner of presentation reads much more like a show and tell of interesting "modern" harmonic practices. This is not an indictment; far from it-Berkman is offering suggestions for interesting and colorful harmonic avenues to pursue, many of which have not been thematized as reharmonizations in quite this way; this makes Berkman's a valuable and unique introduction to this aspect of contemporary jazz practice.

There is a great deal of valuable material in Berkman's book. My caveats above notwithstanding, the concentric-circle model is pedagogically intriguing, and seems like a highly practicable entry into harmonic substitution. The book

\footnotetext{
35 Terefenko's examination of "Stella by Starlight" is informed by a series of analyses from the special session "Alternate Takes: Stella by Starlight," which took place at the Society for Music Theory annual conference in 1997 and was published in Annual Review of Jazz Studies 9 (1997). He describes the relationship between the commonly-played jazz changes and both the original sheet music and the film version, and demonstrates how the jazz changes function as "a middleground elaboration of the original progression" (Terefenko, 380).

${ }^{36}$ Most unfortunately, Berkman's defense is the weakest part of this narrative: he sidesteps a close engagement with harmonic function with a Peanuts quote ("of all the Charlie Browns out there, you are the Charlie Brown-iest"), which would be clever except that it supports the exact opposite reading of the one he is trying to convey (62).
} 
is full of constructive musical examples (and the recorded tracks are lovely), and the way that Berkman weaves his vast experience as a high-level New York performer into his narrative demands that we pay close attention to what he is saying. Berkman is at his best when he is proselytizing for a rigorous approach to deep learning (see p. 108, for instance). He has tremendously useful advice on practicing, transcribing, and listening, and as Fred Hersch says in his inside-cover testimonial, "the 'Tips for Composers' alone are worth the price of the book." And he constantly advocates for bringing technical rigor and creative exploration into conversation with one another, as in: "[t]he marriage of intuition with rational development and exploration of ideas and harmonic structures that interest you can be extremely productive" (152).

I have three overarching concerns with Berkman's book, all of which relate to the editorial process and the way in which the book was or was not peerreviewed or otherwise carefully vetted before publication. The first of these is the book's tone. Berkman's metaphors and humorous asides often manifest as a welcoming casualness and warm sense of humor-never a bad idea when introducing complex materials in the classroom. It quickly becomes a distraction, however, and detracts from a serious engagement with the subject matter. Sometimes there's a bit of subterfuge at play as well, when Berkman's casualness disguises an unwillingness to closely engage a subject-there are several points at which the reader is given a very unfortunate "that's just the way it is" deflection that's more than a little disappointing. ${ }^{37}$ And then a few of Berkman's jokes, while well-intended, have no business in an inclusive educational setting: a joke about singers and "My Funny Valentine" (86) was never funny to begin with, and a reference to that most galling of descriptors in jazz culture, "killing"-which needs to be put to rest for any number of reasons-is jaw-droppingly inappropriate and potentially offensive (78).

The second aspect of Berkman's tone is a puzzlingly confrontational attitude that emerges when referring to his experience with students. These manifest as insinuations that students are not willing to invest the time to deeply engage their subject matter (c.f. pp. 36-37; 57), as implications that students do not appreciate the complexity of a certain kind of modern jazz practice (c.f. pp. ii, iii, 19, 43, 60, 81) and as straw man critiques that suggest that students don't creatively engage the tunes they play. ${ }^{38}$ Throughout his

\footnotetext{
${ }^{37}$ Not to say disingenuous: it's best to avoid making epistemological claims if one cannot, or will not, see the argument through.

${ }^{38}$ While there are many troubling passages, perhaps the most egregious is an account of a dialogue with a composition student:
} 
narrative there is a conflation of more complex with better (c.f. pp. 132-133), which is a subtext of some of the confrontational remarks about his student experiences. ${ }^{39}$ There is also an unwillingness to engage streams that have been taken up in recent years (chord inversions, the expressive value of simplicity and harmonically uncrowded lyricism), which in my experience is what many students are responding to and investigating.

The biggest issue with Berkman's book is that it doesn't seem to have been vetted either by peer review or careful internal editorship. There are many typos and missing punctuations, inconsistent chord symbols, "\#" and "b" instead of proper sharps and flats, awkward sentence constructions and grammatical infelicities, mistakes in musical examples, and in at least one case a wrong example inserted (p. 57). More important, though, there are some conceptual errors and incorrectly- (or at least highly idiosyncratically-) defined terms: in addition to the aforementioned passing chords that don't pass and a definition of "cadence" that does not engage a very long and consistent history of usage, he introduces many terms without defining them (including some fundamental terms like intervals and minor keys, technical terms like montuno, and concepts like melodic improvisation-what a non-pianist might do with the information in the book), and quite a few of his ascriptions of harmonic identity are questionable.

\footnotetext{
I am often reminded of the time I had a rather stubborn student bring in a tune with the chord changes: C-6 to F7 to B bmaj7. I asked him if he REALLY needed that chord to be a C-6, or might it actually be better and simpler as a C-7 since the C-6 in this context, to my ears anyway, was a weaker choice than $\mathrm{C}-7$, harder to voice and minimizing the effect of the dominant that came in the next bar. "Oh no," he assured me, "I'm the composer and that's what I want. It has to be that." Well, true he was the composer, but that doesn't prevent him from being wrong. In general, especially in the world of non-functionality...you have to want that particular chord and not another. Intention matters. (181)
}

There are many problems with this narrative, including the puzzling assertion that C-6 is somehow inappropriate (made worse with a weak "in my opinion" caveat), and that "it's harder to voice" is a legitimate argument for avoiding a chord, but the most glaring is the blatant contradiction of calling out a student for wanting a particular chord and then suggesting that somehow that was not the chord the student wanted. Yes, intention matters, and intentionality is exactly what the student was demonstrating.

${ }^{39}$ For example, "If [a student] plays the same standard chord changes as the 'Real Book' version of the tune I wonder: 'What are you trying to say in your personal statement of the tune? Why not try and use harmonic substitution to let the listener feel what you think about this tune-to tell a story and to create drama and emotion"' (60). Berkman tries to backpedal from his implicit value judgment, but the proscriptive damage is done-reharmonization emerges as the only means to create a personal connection with the tune. 
Take the viiø7 chord, diatonic in major keys. Berkman locates this as a dominant-functioning chord (as, we'll see, does Terefenko-see Berkman, 13 and Terefenko, 44). Mulholland and Hojnacki, on the other hand, state unequivocally that as dominant-functioning chord, viiø7 "is not an alternat[ive]" (Mulholland and Hojnacki, 8). Their rationale is that while viiø7 fits "the definition of dominant function" (referring to the constituent tritone that it shared with V7), "in the last hundred years, it has been used so rarely in this way that it can be excluded from the dominant category." Indeed, a cursory corpus study of jazz tunes, and consultation with a few musicians immersed in post-bop jazz, has revealed no instances of dominant-functioning viiø $7 \mathrm{~s}$ admittedly this is far from a rigorous study, but it suggests that they are indeed quite rare. Berkman and Terefenko both accept a dominant-functioning viiø7, and Terefenko even carefully teases out a notational distinction between $\varnothing 7$ (describing dominant function; viz. $\mathrm{D} \varnothing 7$ as viiø7 in $\mathrm{Eb}$ ) and $\min 7(\mathrm{~b} 5)$ (describing pre-dominant function; $\mathrm{D} \varnothing 7$ as iimin7(b5) in $\mathrm{C}$ minor). Tellingly, neither Berkman nor Terefenko provide examples of a dominant-functioning viiø7 in context.

Berkman takes viiø7 usage even further, suggesting that it is a viable target of tonicization, approached by its ii-V (20). Mulholland and Hojnacki again refute this convincingly, describing how viiø7 "is so unstable... it is meaningless as a target chord" (Mulholland Hojnacki, 42). This is consistent with most accounts of leading-tone harmony.

Another problematic ascription of analytic function is how Berkman describes chains of applied dominant chords, where, say, $\mathrm{V}$ is approached by $\mathrm{V} / \mathrm{V}$, which is approached by $\mathrm{V} / \mathrm{V} / \mathrm{V}$, which in turn is approached by $\mathrm{V} / \mathrm{V} / \mathrm{V} / \mathrm{V}$ (30). I prefer to think of chains of applied V7 chords in terms of their individual resolution-implications, as in $\mathrm{V} / \mathrm{vi} \rightarrow \mathrm{V} / \mathrm{ii} \rightarrow \mathrm{V} / \mathrm{V} \rightarrow \mathrm{V}$, emphasizing that it is at the point of resolution that the identification of the target is revealed as a new dominant, and therefore that through the temporal life of some particular chord it still points to its expected (in this case diatonic) target. Mulholland and Hojnacki's arrow notation mitigates this quite well, by the way-see their p. 50.

Berkman offers a strangely flippant and cursory introduction of minor keys, asserting outright that minor-key tunes are not as interesting as those in major keys (Chapter 8 on the minor mode-in my opinion the least successful thread in the book). There are also quite a few unsubstantiated assertions and subjective claims that I wish were more carefully developed (forward motion on 39; "it feels wrong to me" (42), "I usually prefer..." (56), "tritone substitution works best for major ii-Vs" (72), "strongest" (74), "it doesn't really matter" 
(109), "macho quality" (125), and quite a few more). Of course there should always be room for an author's subjectivity (especially in a textbook that draws upon that author's vast experience in the classroom), but some of these claims should be presented with more nuance and greater sensitivity to alternative viewpoints.

One particularly troubling passage is an examination of the harmonic structure of Antonio Carlos Jobim's "Triste." Here Berkman makes a case for a chord that he prefers over the chord that appears in one well-known fake book version. But in a brief aside Berkman relates that "one of my Brazilian students pointed out that the original changes of Jobim's are D-7 (iii-7) instead of the $\mathrm{Bb}$ Major7, and where I use the II7, Jobim uses a biii $\operatorname{dim} 7$ th $(\mathrm{C} \# \operatorname{dim} 7)$ to lead to the ii-7 chord." (55; chord orthography sic.) For all of his insights and admonitions about carefully engaging tunes, studying exemplary recordings, and so on, why does Berkman not take Jobim's chords seriously, in the same way that he would encourage us to do with, say, Kern's (as he does elsewhere in a close reading of "All the Things You Are")? In other words, why should the reader care if an author prefers one chord over another if neither of them is the actual chord that the composer intended?

\section{A HOLISTIC APPROACH}

Dariusz Terefenko's Jazz Theory: From Basic to Advanced Study signals an admirable attempt at a comprehensive, integrated introduction to the elements of jazz practice, including harmony, melody, form, notions of variation, prolongation, and diminution, and at least some conceptual aspects that inform the act of improvising. It is intended as a textbook for a four-semester course on jazz theory. As such, it is considerably longer than the volumes described above, and is more immediately pedagogically-oriented, with an extensive online workbook with exercises and examples, and with considerable attention given to introductory concepts that are assumed by Mulholland and Hojnacki and Berkman (notes and intervals, rhythm and meter, chord inversions, and so on). It also takes analysis seriously, to which I will return below. For these reasons it is somewhat unfair to compare with the previous volumes, since its aspirations diverge wildly. But Terefenko's very attempt at comprehensiveness opens an important question regarding the two volumes that focus more modestly on harmony: to what extent does it make sense to address harmony removed from other aspects of musical process? Both Mulholland and Hojnacki and Berkman do consider other aspects, but in a cursory way. Again, this is by design: the titles of the two volumes both foreground the word 
harmony, and both assume that other aspects of jazz syntax are being internalized by the student elsewhere. We should ask: what are the advantages and limitations of compartmentalizing parameters? What values emerge from synthesizing them?

One area where the compartmentalized approach falls short is in the relationship between voice leading and harmonic motion. Both Mulholland and Hojnacki and Berkman ignore voice leading in most of their musical examples (at one point Berkman comments that, regarding one of his examples, the "harmonizations are improved by good voice-leading in the inner voices of the chords" (Berkman, 33) but then suggests that those considerations are not important for non-pianists, as if voice leading need not be a consideration for melodic improvisers). Terefenko, on the other hand, reminds the reader constantly that voice-leading principles guide harmonic activity in jazz every bit as much as they do in earlier music; for example, "[w] hen jazz musicians think about dissonance treatment or highlight a linear approach to harmony as opposed to a vertical one, they rely just as much on well-defined rules of voice leading as do composers of common-practice music" (Terefenko, 33).

Further support for an integrated approach is in the irreducible connection between harmony and meter and rhythm. As described above, Mulholland and Hojnacki's introduction to harmonic rhythm is commendable, especially in the way that it focuses the dependent relation between ii and $V$ as an essentially metric event. While Terefenko does not engage metric concerns to such a detailed degree, he does offer much useful advice, such as in an aside on chromaticism:

The effective use of chromaticism depends on a solid sense of time and good voice-leading skills. Chromatic notes that are foreign to the diatonic framework require correct preparation and resolution. Since the preparation and resolution of chromatic notes are inherently rhythmic, the voice-leading forces that control them have important rhythmic as well as melodic implications. (90)

This is sound advice, even if it is disappointing that no specific examples are provided in its support. Similarly, in his detailed analysis of Rodgers and Hart's "Have You Met Miss Jones?", Terefenko describes how formal, tonal, melodic, and harmonic processes should be considered, asserting that "[i]t is not sufficient...to consider these categories as separate entities, but [one should] examine them in relation to one another" (332). This is a crucial point, and while it presents a pedagogical challenge, it should be incumbent on the teacher to be thinking in terms of the irreducible interrelationships between these musical strata even in the early stages of teaching jazz theory. 
Terefenko's book is divided into three parts: basic, intermediate, and advanced. The first part covers fundamentals and extensive information about chords, scales, voicings, chord progressions, modal relations, and blues. The second section extends all of these into various idiomatic territories; several lengthy excursions into bebop form the central focus here. The advanced section introduces pentatonic and hexatonic structures, and also develops a rigorous approach to thinking about phrase structure and song forms. Terefenko concludes with an introduction to post-tonal procedures, about which more below.

An important theme emerges early in Terefenko's book about the particular types of interactions between meter and rhythm that we call syncopation. Terefenko begins by defining metric and phenomenal accents, and proceeds to describe what happens when they are in disagreement, using one particularly pervasive rhythmic motif, the "Charleston" rhythm, as a case study for how to generate varied but also motivically unified rhythmic motion within a periodic metric context (122). ${ }^{40}$ He continues to use the Charleston rhythm as a generator for syncopated activity through most of the subsequent rhythmic examples. The role that this rhythm plays could be developed even further: the Charleston rhythm is equivalent to the first two onsets of the tresillo rhythm, which in turn is the first half of "3-2 son clave," which as Christopher Washburne (1997) has demonstrated informs many rhythmicmetric structures in jazz. Between Washburne's observations and the detailed study of tresillo-clave interactions in rumba that David Peñalosa has described in rich detail, there is firm ground for exploring some of the rhythmic possibilities afforded by Terefenko's Charleston rhythm, and indeed Terefenko's displacements and Peñalosa's quinto locks have much in common. ${ }^{41}$ One of the hallmarks of Terefenko's book is how, having introduced the rhythmic possibilities of the displaced Charleston rhythm, he infuses it into many of his musical examples and exercises, reinforcing the close relationship between rhythm, melody, and harmony that is essential to jazz practice.

\footnotetext{
${ }^{40}$ I prefer to align with Kofi Agawu and avoid words like "disagreement" when describing the ways in which syncopated rhythmic gestures interact with periodic meter. Agawu challenges A.M. Jones's "clash and conflict" evocation of African rhythm, suggesting that "clash and conflict' are antithetical to African traditional philosophy, which is more likely to be communal and cooperative" (Agawu 2003, 78).

${ }^{41}$ See Peñalosa (2010). One small complaint is that Terefenko appears to have copied and pasted the Charleston rhythm in Finale in some of his musical examples, which results in some ambiguous rhythmic notation.
} 
Terefenko is willing to dig deeply into the foundation and the functional identities of the harmonic objects of jazz. He provides an account of their triadic basis that also acknowledges the syntactic privilege that seventh chords hold, an opinion that is shared by all of the authors being considered in this study, as well as by most contemporary jazz theorists. He clearly demonstrates how the tonic-pre-dominant-dominant-tonic (T-P-D-T) model for harmonic progression plays out in jazz practice (26-28; 43-44), he explains the role that cadences play as phrase boundary markers (and goals of harmonic motion; 31), he engages the co-constitutive roles that counterpoint (and voice leading) and harmony have on one another (33-34), and he introduces the reader early on to the important concept of prolongation, which becomes an underlying theme through much of his narrative and assumes a central position when Terefenko starts to outline the different kinds of phrase models that comprise tonal jazz practice (Chapter 21). Because Terefenko is carefully guiding the reader toward thinking in terms of T-P-D-T as the fundamental design that describes most harmonic motions, he brackets a few other types of harmonic actions (IV to I, for instance, or the stepwise harmonic motions that Mulholland and Hojnacki account for in their narrative); a tacet assumption is that these motions are better explained as prolongational actions, which with the exception of the blues-derived IV to I I tend to agree with.

Prior to his introduction of the T-P-D-T model, Terefenko offers fourteen seventh chord types (39-41), and he begins to consider notions of chord substitution and harmonic prolongation via functional categories (major, minor, dominant, and "intermediary") placed in functional "families" (tonic, pre-dominant, and dominant) that are conditioned by diatonic possibilities in major or minor keys (43-46). The density of information in this exposition is impressive but perhaps a bit daunting, and feels at times like something of a grab-bag as essential and comparatively rare harmonic objects are presented all at once. Mulholland and Hojnacki are careful to describe harmonic moves that are common in mainstream jazz practice. Terefenko, on the other hand, offers all diatonic possibilities as if equally valid and equally unproblematic. In major keys, the only chord that might raise eyebrows is the dominant-functioning viiø7: while certainly logical, one is hard-pressed to find examples of it actually being used in the literature (see the Berkman discussion above). In minor keys (which Terefenko, as do the previous authors, rightly casts as the union of natural, harmonic, and melodic minor), there are a few chords that we might question: ii7, \#ivø7, and again the dominant-functioning viiø7-the first might be better explained as borrowed from the parallel major key (via mode mixture), the second as an applied chord or in a chromatic sequence (a prolongational 
role), and again the last just doesn't seem to occur. More important, the ii7 suggests that Terefenko is, if briefly, falling into the trap of chord-scale isomorphism where the chord-scale (either Dorian or melodic minor in this case) is presented as an uninterpreted smooth space, prior to striation by voiceleading concerns or diatonic trajectories. Fortunately this is a small matter, and for the most part Terefenko adeptly avoids these kinds of mischaracterizations of tonal behaviors.

Terefenko does an admirable job of contextualizing harmony within a more holistic core curriculum model. Because of this turn to holism, along with the limitations of print media (no one wants an 800-page textbook!), there can be something of a kitchen-sink effect as Terefenko tries to touch on everything. The result is that some topics lack depth or immediately apparent connection to the rest of the book. I would point out rhythm (especially harmonic rhythm), how non-chord tones behave and how they can be used expressively, and the improvisational possibilities of these materials as a few areas that could be developed and integrated further. But still, there is a great deal to admire, and even in the areas that fall somewhat short there are still valuable passages. For instance, the brief chapter on improvisation (Chapter 10) is loaded with useful conceptual information-riffs and repetition, using guide tones to shape more elaborate gestures, and motivic development-and packs in a number of valuable examples for practice and inspiration. The examples on pp. 125-6, linking chordal thirds or sevenths through idiomatic melodic gestures, are particularly valuable in this regard.

There are three aspects of Terefenko's book that stand out as exemplary contributions to jazz theory pedagogy. The first is his introduction of posttonal resources to harmonically-based jazz practice, which he accomplishes by extrapolating from the concept of upper-structure triads to encompass all trichord types (408-419). ${ }^{42} \mathrm{He}$ groups trichords into loose similarity classes for ease of comparison (408), and exhaustively outlines their potential in harmonic and modal contexts. While a number of recent books introduce particular aspects of post-tonal strategies to improvisational contexts (including O'Gallagher (2013) and Yamaguchi (2011)), Terefenko's is the first to do so within the context of a core curriculum. He also provides a clear introduction to set-class terminology, including integer notation, inversional equivalence, interval vectors, and more, and makes a strong case for the value of thinking in those terms for the improvising musician.

\footnotetext{
${ }^{42}$ While there have been a number of important applications of post-tonal theories to "free jazz" (c.f. Block 1990 and 1993), the way that Terefenko incorporates them into tonal jazz contexts amounts to a new way to consider thinking about extending chromatic resources.
} 
Another compelling feature of Terefenko' text is his explication of a number of basic phrase models for standard song forms (Chapter 21, pp. 290322). He does this first by probing deeper into the nature of the coconstitution of melody, harmony, voice leading, and phrase structure. He then describes, in compelling detail, the three main parts that constitute a phrase (phrase identifier, harmonic departure, and cadential confirmation; p. 290-a comparison with Berkman's explanation of cadence amplifies some of the latter's flaws), and suggests some avenues for composing out phrases based on deeper-middleground contrapuntal archetypes. Terefenko's "jazz rule of the octave" is useful and emphasizes the relationship between teleological harmonic motion and the "downward" motion that it animates (292-4). His phrase models, which derive in part from earlier scholarship by Strunk and Martin, invite the reader to begin to understand the large-scale unfoldings of song forms, stepping back from a focus on local harmonic motions (which is what most jazz texts limit themselves to), to consider increasingly long prolongational actions. ${ }^{43}$ There are invaluable possibilities here for improvisers and composers: thinking about crafting improvisational utterances that flow along harmonic trajectories (see the discussion of "Blues for Alice" above, for example), and composing from the perspective of understanding these trajectories, how they work, and what they mean expressively. All told, Terefenko offers thirteen basic phrase models and provides lists of jazz standards that incorporate them. From phrase models Terefenko takes us to song forms, again offering logical categories and good examples. He goes far beyond simple description of gross formal designs (AABA, ABAC, etc.) to consider the types of actions that engender certain kinds of typical harmonic relationships within those formal archetypes. This includes an excellent list of tunes organized by the keys of their respective bridges (330-331). There is much value in considering various tunes comparatively in this way; a great deal is revealed about compositional design and improvisational potential.

The third feature is Terefenko's detailed and attentive analyses. These range from harmonic analyses of tunes (c.f. his reading of "My Romance," in which he introduces second-level analysis (136-138), even drawing parallels between foreground / middleground relations and the ways that jazz musicians talk about harmony ${ }^{44}$ ) to annotated transcriptions of complete solos (including two by pianist Hank Jones, on "Moose the Mooche" (245-251) and

\footnotetext{
${ }^{43}$ See p. 322, fn 6 on Martin, for example.

${ }^{44}$ I don't agree with all of Terefenko's analytic claims-viz. a second-level I7 (m. 8) and bVII7 (m. 14) in his "My Romance" analysis-but of course there is always room for alternative explanations in these sorts of situations.
} 
"Confirmation" (232-237) respectively). One of the highlights of the book is Terefenko's close reading of Lennie Tristano's "Line Up" (385-395), which amounts to a thorough exigesis of an improvisational language that has been both hugely influential (through Tristano's decades of teaching and his body of recorded work) and under-represented in most jazz methodologies. Terefenko's annotated transcription reveals many fundamental aspects of Tristano's linear improvisational language-rhythmic displacement, melodic interpolation, "playing outside," motivic parallelism, compound melody, and more-and suggests avenues for the reader to experiment with these and similar developmental techniques.

\section{ON REHARMONIZATION}

The role of reharmonization in Terefenko's methodology differs radically from that of Berkman, in ways that transcend the simple fact that it is given a single chapter in the former, whereas in the latter it serves as the singular focus of an entire book. Terefenko begins, as does Berkman, with Bach, this time by comparing three of Bach's harmonizations of the chorale "Herzlich tut mich verlangen." Terefenko effectively describes how Bach's various harmonizations recontextualize the chorale melody, drawing attention to different features and trajectories, while acknowledging that "[e]ach phrase receives harmonic support that clearly delineates the underlying tonality and effectively drives to a cadential repose" (359). He goes on to enumerate some important parallels between variation technique and reharmonization that open up compelling avenues for further comparative research. All of this sets up his main thesis for the chapter, which describes a number of "basic reharmonization techniques"-adding extensions, expanding structural harmonies, tonicization, tritone substitution, passing and neighbor diminished seventh chords, pedal points, "functional exchange" (which is sort of like Berkman's mode mixture), "melodic recontextualization" (which seems like a catch-all for substitutions not well described by one of the other techniques, and is perhaps slightly tautological), and "interpolation of auxiliary progressions," which combines several of the above.

While comparatively brief, Terefenko's account of reharmonization resonates with Berkman's concentric circles. In his introduction, Terefenko explains how "[w]hile these newly created harmonic modifications might be quite substantial, they are usually traceable to and motivated by the original chord changes." (358) These traces are clearly evident in his subsequent examples, which take various phrases from "Autumn Leaves" to illustrate how different reharmonization techniques might be applied, and how they relate 
both to the original melodic and harmonic structure of the tune and to other, less complex modifications (363-374).

A comparative look at the relative weight that Terefenko and Berkman give to reharmonization invites some real ontological questions about the status of various objects and processes in jazz, and what kinds of essential features are revealed by particular epistemological orientations. For Terefenko, reharmonization is something you do after careful engagement with the original tune and with exemplary recordings, and through close scrutiny of harmonic functions, teleological processes, and voice-leading actions. For Berkman, reharmonization is always already part of the act of learning a tune: this is evidenced positively through the essential role his concentric circles play in thinking through harmonic relations, but negatively through his occasional disregard of composer intent (as the "Triste" example described above demonstrates).

\section{ChORD-SCAlES, ChORD-SCAlE TheORY, AND ChORD SPECIFICITY}

One of the more robustly debated aspects of the Berklee system is the relative importance it gives to chord-scale relations. ${ }^{45}$ Mulholland and Hojnacki alternate between two basic narratives: that chords derive from scales ("[a] source scale is the scale from which a chord is derived"; p. 84), asserting an ontological priority for the latter, and that chords and scales are fully isographic, represented by the hybrid term "chord-scale." Both of these themes make assertions about causality and harmonic identity that we should approach cautiously.

What is frequently lost in chord-scale theory narratives is that while a scale identifies a particular sonic space, giving us a sense of the relative relationships between the pitch classes that comprise it, some of the behavioral tendencies of those pitch classes, and what Terefenko calls the "beauty mark" or the identifying feature or features of a tonal collection relative to other collections in a kind of loosely defined similarity class, scales do not define the features of the chords with which they interact. This is true even in the most basic diatonic settings. To take a very simple example, the fourth scale degree of the major scale (which I would like to distinguish from Ionian, about which below) is not an "avoid note"-it is an essential tonality-defining (or at the very least tonality-supporting) note that functions as a consonance (say, the third of a pre-dominant ii chord), an active tone driving toward resolution (as the seventh of V7), or an expressive dissonance (say, a suspension on the I chord),

${ }^{45}$ See Ake $(2002,123-126)$ for one particularly well-framed critique. 
depending on its local harmonic context. Of course many conventional chordscale narratives attempt to recast this fluid tonal space by reorienting the major scale through three different modal configurations (Dorian, Mixolydian, and Ionian respectively), but by doing so they greatly overdetermine the role that modes play in tonal contexts. While these narratives are intended to offer a useful scale or mode to help the novice student hear and navigate harmonic motions, Mulholland and Hojnacki's chord-scale theory asserts that chords and scales are essentially the same thing, and that the former derives from the latter. ${ }^{46}$

While Mulholland and Hojnacki assert that chord $x$ derives from scale $X$ in a dependent and causal relation, Terefenko prefers to focus on the performer's agency, suggesting that "we can establish a relationship between" chords and scales (102); in other words, chord-to-scale mapping is an act that we perform; a choice we make. Berkman, too, reinforces the fact that "as a soloist I have many, or at least several, chord scale options for each type of chord.... I say 'chord scale' but I prefer to think of these as a set of notes that ... I can dip into, using any members of the set at my discretion" (89). This is a sensible view. ${ }^{47}$ Both Terefenko's and Berkman's views resonate with that outlined in Jamey Aebersold's "scale syllabus," which as David Ake has described offers a number of possible scales, arranged in order of relative dissonance in relation to a shared chordal correlate (see Ake 2002, 123). Rather than being fully isographic (as Mulholland and Hojnacki assert), Aebersold's is a one-to-several mapping, and both Berkman and Terefenko suggest that we can loosen even that one-to-several relation in favor of a larger plurality of possibilities. I suggest that we take this much further and explore what possibilities arise when no scales are considered; when the notes that comprise a harmonic space are taken as points of orientation and the improviser imagines any number of

\footnotetext{
${ }^{46}$ There is one encouraging slip where Mulholland and Hojnacki suggest that "[t]he chord scale for io7 is created by spelling the chord tones, and then connecting them with scale tones that are diatonic to the parent key" (160, emph. added).

${ }^{47}$ Berkman also suggests that "tensions are discrete colors that don't want to do anything in particular except bring color to the chord voicing" (90), which is less tenable; compare this with Strunk's definition of tensions as pitches "related to a structurally superior pitch (usually a chord tone) by step, such that the tension represents and substitutes for the structurally superior pitch, called its resolution, in the register in which it occurs" (Strunk 1985, 98). Berkman's conception here practically demands the more neutral term "extensions," which I prefer in any case to describe additions to basic seventh-chord structures.

Earlier, Berkman asserts that diminished seventh chords "have an 8-note symmetrical scale" (22). Again, chords do not have scales; they may be associated with scales if so desired.
} 
linear paths to get from one point to another, including those that leave twelve-note ET space to consider microtonal possibilities. ${ }^{48}$

Chord-scale relations are established, not given a priori, and there is no priority given to one or the other. This is the ontological mistake that most chord-scale theory narratives (including that of Mulholland and Hojnacki) make- that scalar collections generate chords, and that modes are generated from a parent ("source") scale. Terefenko does the best job I have seen of carefully avoiding causal language, even if it occasionally results in some complicated linguistic constructions (viz. "chords that establish a relationship with the Phrygian mode" (102)). Of course the counter-argument here is that chord-scale theory is intended as a pedagogical tool and that as such it necessarily prescribes certain actions; Terefenko makes this clear when he reminds the reader that "[o]ne of the goals of chord-scale theory is to develop our practical skills" (105). The danger, as Ake, Rawlins, and others have pointed out, is that it forecloses the most important actions and establishes a cognitive barrier to thinking in terms of voice leading and harmonic progression by focusing overly on the behaviors of single chords or chord-scales.

An example of this is the interplay between $\hat{\sigma}$ and $b \hat{\sigma}$ in minor. In Mulholland and Hojnacki's Figure 4.14 (p. 88), a relation might be established between the m.1 C minor chord and a Dorian or melodic minor scale (both featuring $\hat{6}$ ), but on the downbeat of $\mathrm{m} .2$ the chordal $A b(b \hat{b})$ reorients us to an Aeolian space. But the leading tone in the G7 chord then denies Aeolian, perhaps pointing us now toward harmonic minor (since that $A b$ is still active in our minds and ears, perhaps manifesting literally as a b9). So in the space of eight beats do we have something like Figure 6 describes?

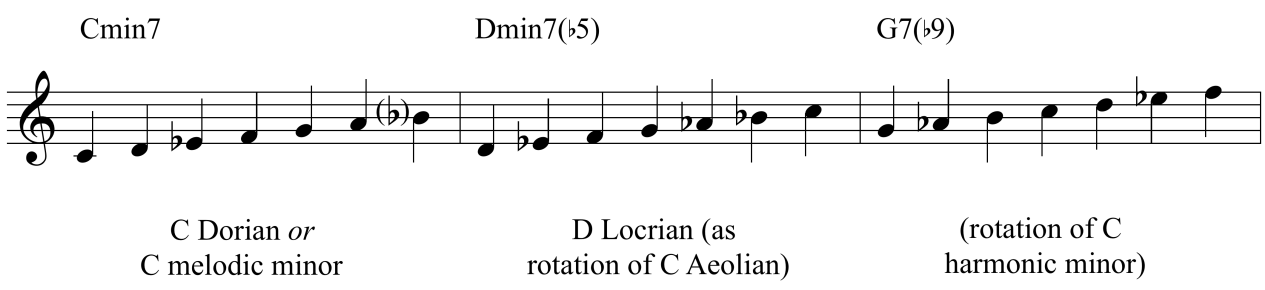

Figure 6. An overdetermined chord-scale reading.

\footnotetext{
${ }^{48}$ This is how I steer my own improvisational syntax, and while I have not yet theorized it sufficiently to construct any kind of robust pedagogical framework for it, it does inflect the way that I teach improvisation and jazz harmony, even at the introductory level.
} 
Of course not. This chord-scale reading completely ignores voice leading and harmonic considerations, a notion of playing through chords rather than on them (see Ake 2002, 126), and the role that a scale can play across a harmonic progression rather than as the correlate of a single chord (see Rawlins 2000, 『19). In his critique of Levine (1995), Rawlins describes how the latter misunderstands how a pitch collection is or is not expressed by a single chord or scale. Rawlins refers specifically to Levine's assertions about harmonic minor, which the latter suggests is not a very useful scale in modern jazz. Rawlins's critique is on the grounds that by thinking of harmonic minor as a scale with a 1:1 mapping onto some chord, that the voice-leading implications that are essentially bound up in the construction of the scale are suppressed; that is, like every scale, but perhaps in a way that is particularly clear, the harmonic minor scale's constellation of voice-leading behaviors is always already present, and that by presenting the scale without closely considering those behaviors one is ignoring the most important and salient aspects of the collection (actions over static things). What this does demonstrate is that there are indeed multiple shades of minor at play in tonal minor contexts, pretty much all the time. This is what I mean above when I suggest that even a well-intended chord-scale orientation forecloses some of the more important considerations that emerge as one chord impinges on the next in a harmonic progression.

Furthermore, all of our authors make assertions about certain "avoid notes" that I would characterize as essential, mode-defining notes (Terefenko calls these "beauty marks" (79), a term that I find somewhat precious but that evocatively describes how those notes relate to their surrounding harmonic spaces). For example, while Mulholland and Hojnacki accurately portray a complete 1:1 mapping of scale to chord between Dorian and the minor 13 chord, when they compare this mapping to that found between the Aeolian mode and its isographically-related chord, they argue that the b6 of Aeolian is to be avoided..$^{49}$ This is curious, because in the same sentence they suggest that "I-7 can be derived from an Aeolian source when a darker sound is desired" (Mulholland and Hojnacki, 87). But if the only note that distinguishes Aeolian from Dorian is suppressed, how can this possibly be a darker sound? This contradicts practice too, where b6 (or b13) is often used to color a chord voicing, specifically to give it an Aeolian flavor. Terefenko does offer $\min 9$ (b13) as a viable chord option (Terefenko, 82), and while Berkman does not, he does offer two other chords that include both the fifth and b13-

\footnotetext{
${ }^{49}$ Terefenko (103) suggests that the $6^{\text {th }} / 13^{\text {th }}$ of a Dorian chord-scale is a non-chord tone, which I disagree with strongly.
} 
Maj7(b13) (which he refers to with the ungainly moniker "Major7 \#5 natural 5"; p. 172) and Cmin9(Maj7, b13) (which he refers to with the equally cumbersome and somewhat ambiguous " $\mathrm{C}$ minor major9 b6"; p. 173)—which suggests that $\min 9$ (b13) should also a viable option in his expansive consideration of possible chord qualities.

We should also consider how $\hat{4}$ behaves in major tonal spaces, and how these sorts of cases reveal important limitations of chord-scale isography. I come from the camp that distrusts the term "avoid note" (and Levine's "handle-with-care note" $(1995,37)$ is little more than a euphemism), and prefer to orient toward a language that engages the expressive value of notes in context. And I have already alluded above to at least two instances when the behavior of $\hat{4}$ is misascribed by various narratives, including especially how an "avoid note" conception begs the question of expression functional identity. A related modal space that is not adequately developed in any of the texts is Ionian, as distinct from tonal major. In Ionian, $\hat{4}$ is an essential mode-defining note; therefore it is imperative that the performer does not "avoid" it if the identity of the mode is to be established clearly. Terefenko mentions this fact in a very brief aside (footnote 1, p. 91), but it would be good to see the idea developed further, to investigate just how a modal Ionian might behave in a jazz context.

A further limitation of chord-scale isography is revealed through a close look at some harmonic objects that neither Mulholland and Hojnacki nor Berkman touch at all, and that Terefenko conflates with enharmonicallysimilar objects: Maj7(b5) and Maj7( $\$ 5)$, and 7(b5) and 7( $\$ 5)$ chords, and more generally the kind of information that is encoded in labels b5 and \#11 (or \#4), and $\# 5$ and b13 (or b6). ${ }^{50}$ The distinction between, say, b5 (as a basic chord tone) and $\# 11$ (as an extension) is subtle but crucial, and speaks to the way that a chord-scale orientation flattens nuanced distinctions between similar but distinct harmonic objects. In order to draw attention to this distinction, I need to make a claim that contradicts many jazz harmony narratives, including those presently under investigation. I suggest that every highest extension indicated in a chord symbol asserts the presence of each lower chord tone, so Cmin11 asserts that there is a ninth, seventh, fifth, third, and root, and DMaj13 asserts

\footnotetext{
${ }^{50}$ Mulholland and Hojnacki do mention Maj7( $\left.¥ 5\right)$ briefly, as a tonic substitution in minor (IIIMaj7(\$5)). Berkman does not list any of these four chords in his "complete set of seventh chords” (24), but does include the Maj7( $\$ 5)$ chord in a very bizarre roster of what at one point he calls "jazz power chords" (125), and which he describes on one hand as having a "static sound" and on the other hand as possessing an "energetic dissonant feeling."
} 
that there is a raised eleventh, ${ }^{51}$ ninth, seventh, fifth, third, and root. In other words, lower chord tones (including extensions below the indicated one, and including the chordal fifth) are given by definition, and we can choose not to play them in a voicing (or in a melodic line), but that is more of an orchestrational decision. So if we are given a DMaj13 chord and play the $\sharp 11$ but not the fifth, a common and legitimate choice, we should be aware that we are playing a $\sharp 11$ and not a b5, and that the fifth is still available as a consonant melodic choice. ${ }^{52}$

On the other hand, DMaj7(b5) is a four-note chord where the fifth is altered. The Lydian scale holds a more tenuous relationship with this chord. Lydian and Maj13 hold an entirely unproblematic relationship with one another (here I disagree with both Terefenko and Mulholland and Hojnacki; there are no avoid notes in this mapping), but Lydian has one note, 5, that clashes with the basic chord tone b5. The fifth of the Lydian scale could still be invoked as a non-chord tone, but then so could any note in the chromatic scale.

A comparison between $7(\# 5)$ and $7($ b13) presents a similarly nuanced distinction. $\$ 5$ means the fifth of the chord is altered, and that therefore there should be no natural fifth. But b13 suggests, again, the syntactic presence of a fifth, which a performer may or may not choose to include in a chord voicing or melodic utterance. By including the fifth, the performer highlights b13's status as an extension, and reinforces the subtle difference between the two sonorities. None of our authors would agree with my claim here: Mulholland and Hojnacki describe the fifth and the b13 as "provisional avoid notes: if b13 appears in a voicing, the [fifth] of the chord is usually omitted and vice versa" (95), while Berkman states that "when b13 is found in a chord, generally the 5 th of the chord is not present" (23; compare this though to his "\#5 natural 5" described above).

Terefenko, too, conflates enharmonic notes in a way that sidesteps considerations about the specific role that each plays (see p. 81 for one example involving $\sharp 4$ andb5). If we hold that scale degrees have unique functions within

\footnotetext{
${ }^{51}$ (by convention, but also reinforcing the co-presence and mutual influence-but not equivalence! - of chords and scales; in this case the Lydian scale).

${ }^{52}$ For all of our authors (c.f. Terefenko 62, fn 2), "13" in the chord symbol requires a seventh but not a ninth. Again, I disagree: the ninth may be omitted in a voicing (just like the fifth may be), but it is implied by the symbol "13." If a composer wants the specific sound of a seventh chord with added thirteenth but no other extensions, the symbol "7(add13)" is a viable solution.
} 
and among the constellations of relations they hold with the remaining notes in a scalar collection-which has been theorized extensively in the context of diatonic spaces as maximally individuated collections; viz. Rahn (1987) - then an assumption of double scale degree function ( $\hat{5}$ and $b \hat{5})$ at best obscures that way of thinking through the expressive behaviors of notes in contexts. Terefenko's motivation is sound here, and does speak to common jazz practice, which tends to bracket the distinction between certain enharmonic objects when practical considerations override theoretically sound ones. I am suggesting that we rethink that distinction moving forward, thereby enriching the horizon of harmonic objects in jazz and how they may be used.

A subtext of any methodology is how syntactic function is derived-where does some particular object or process come from; what is its theoretical scaffolding or underlying framework? For Mulholland and Hojnacki the scaffolding is transparent and consistent: the source scales that chords are derived from. Berkman's syntax derives entirely from diatonic and chromatic substitutions of subdominant, dominant, and tonic archetypes. Terefenko, too, begins with a basic functional model that engenders many different types of substitutive functions, and at one point offers an intriguing scaffolding model that locates applied Vs and ii-Vs as permutations of passing and neighbor diminished seventh chords (Terefenko, 68-76). Terefenko's model differs from Berkman's primarily in that for the former, the background structure of the tune-its fundamental harmonic and voice-leading framework-animates those substitutions at all times, in a hierarchical manner, while the latter offers a more rhizomatic account of the ways in which reharmonizations can relate to their prototypes. Again, there are advantages to both of these ways of thinking, and much can be gained by a careful comparision of their respective directions.

Through a comparison of all three volumes, we can entertain a pretty thorough résumé of the issues that confront jazz theory pedagogy today. These include:

- making determinations about functional identity and how to extrapolate from fundamental functional categories,

- considering carefully just what kind of a relation a chord-scale relation is,

- continuing to consider how voice leading aids and abets harmonic motion, and how chord-scales do or do not represent the kinds of foreground or background linear motions that constitute voiceleading behaviors,

- making careful distinctions between chord extensions, chord-scales, and non-chord tones, 
- engaging the relative specificities of composer/arranger intent, especially from the perspective of chord symbols,

- asking seriously what the study of jazz harmony is supposed to do for students of jazz, and then continuing to shape jazz harmony pedagogy to reflect those goals,

- considering how harmony does or does not intersect with other aspects of the musical fabric, and again thinking seriously about how harmony is taught, and (perhaps) imagining alternatives,

- considering how analysis and the study of harmony reflect the temporal experience of the music it addresses,

- considering how analysis and the study of harmony can engage interactive improvisational considerations.

To this last point, there are stirrings of an epistemic change in the air, as more and more scholars, teachers, and practitioners are starting to imagine how the act of improvisation education (including but not limited to jazz) might be inverted to begin from an interaction-first perspective. David Ake (2012) has speculated about this, and recent work by Hodson (2007), Mazzola and Cherlin (2011), and some of the authors mentioned in footnote 3 above suggests fruitful avenues for using the doing of interactive improvisation as a starting point for thinking through the syntactic spaces required for its success (including harmony, melody, rhythm and meter, timbre, and the rhizomatic webs that link them). In this respect the three volumes under consideration in this essay might be said to represent the culmination of several decades of thought on how to theorize jazz harmony and how to present that information in a way that is both clear and musically useful. For this sort of presentation, the authors (necessarily?) disregard many aspects of how this information should be used, including especially how it might be used in interactive, temporally fluid situations. If, as the various architects of the epistemic change alluded to above suggest should happen, a radical shift occurs in how the doing of jazz improvisation is taught, then perhaps it is incumbent to imagine a way of considering harmony that emerges from that interaction-a collective enunciation that determines what sorts of syntactic processes it needs for its success. What these sorts of radical reimaginings could mean for jazz theory pedagogy remains to be seen, but the possibilities are enticing.

\section{REFERENCES}

Agawu, Kofi. 2003. Representing African Music: Postcolonial Notes, Queries, Positions. New York: Routledge. 
Ake, David. 2002. “Jazz 'Traning: John Coltrane and the Conservatory.” Jazz Cultures. University of California Press: 112-145.

. 2012. "Crossing the Street: Rethinking Jazz Education." In Jazz/Not Jazz: The Music and its Boundaries, edited by Charles Hiroshi Garrett and Daniel Goldmark. University of California Press: 237-263.

Arthurs, Daniel. 2011. Reconstructing Tonal Principles in the Music of Brad Melhdau. $\mathrm{PhD}$ diss., University of Indiana.

Bailey, Derek. 1993. Improvisation: Its Nature and Practice in Music. New York: Da Capo.

Benadon, Fernando. 2009. “Time Warps in Early Jazz." Music Theory Spectrum 31/1: $1-25$.

Berkman, David. 2007. The Jazz Musician's Guide to Creative Practicing. Petaluma, CA: Sher Music Publications.

Berliner, Paul. 1994. Thinking in Jazz: The Infinite Art of Improvisation. Chicago: University of Chicago Press.

Biamonte, Nicole. 2010. "Triadic Modal and Pentatonic Patterns in Rock Music." Music Theory Spectrum 32/2: 95-110.

Block, Steven. 1990. "Pitch-Class Transformation in Free Jazz." Music Theory Spectrum 12/2: 181-202.

. 1993. "Organized Sound: Pitch-Class Relations in the Music of Ornette Coleman." Annual Review of Jazz Studies 6: 229-252.

Braxton, Anthony. 1985. Tri-Axium Writings. Dartmouth: Frog Peak Music.

Brinner, Benjamin. 1995. Knowing Music, Making Music: Javanese Gamelan and the Theory of Musical Competence and Interaction. Chicago: University of Chicago Press.

Christensen, Thomas. 2004. Rameau and Musical Thought in the Enlightenment. Cambridge: Cambridge University Press.

Dubiel, Joseph. 1990. “When You Are a Beethoven': Kinds of Rules in Schenker's 'Counterpoint'." Journal of Music Theory 34/2: 291-340.

Dunsby, Jonathan et al. 2014. "Minor Dominant in Minor Mode?" https://discuss.societymusictheory.org/discussion/128/minor-dominant-in-minormode (accessed 31 January, 2015).

Gross, Austin. 2011. Bill Evans and the Craft of Improvisation. PhD diss., University of Rochester. 
Haerle, Dan. 1982. The Jazz Language: A Theory Text for Jazz Composition and Improvisation. Miami, FL: Warner Bros Publications.

Hodson, Robert. 2007. Interaction, Improvisation, and Interplay in Jazz. New York: Routledge.

Jaffe, Andrew. 1983. Jazz Theory. Dubuque, Iowa: William C. Brown.

Larson, Steve. 1996. "The Art of Charlie Parker's Rhetoric." Annual Review of Jazz Studies 8: 141-166. 2009. Analyzing Jazz: A Schenkerian Approach. Harmonologia Studies in Music Theory. New York: Pendragon Press.

Lehman, Stephen H. 2012. Liminality as a Framework for Composition: Rhythmic Thresholds, Spectral Harmonies, and Afrological Improvisation. DMA diss., Columbia University.

Levine, Mark. 1995. The Jazz Theory Book. Petaluma, CA: Sher Music Publications.

Lewis, George. 1996. "Improvised Music After 1950: Afrological and Eurological Perspectives.” Black Music Research Journal 16/1, 91-122.

Martin, Henry. 1980. Jazz Harmony. PhD diss., Princeton University. . 1988. "Jazz Harmony: A Syntactic Background." Annual Review of Jazz Studies 4: 9-30.

. 1996. Charlie Parker and Thematic Improvisation. Lanham, MD: Scarecrow Press.

1997. “Jazz Theory: An Overview.” Annual Review of Jazz Studies 8: 1-17.

2012. "Charlie Parker and 'Honeysuckle Rose': Voice Leading, Formula, and Motive. Music Theory Online 18/3.

Mazzola, Guerino, and Paul B. Cherlin. 2011. Flow, Gesture, and Space in Free Jazz. Springer-Verlag Berlin Heidelberg.

McFarland, Mark. 2012. "Schenker and the Tonal Jazz Repertory: A Response to Martin.” Music Theory Online 18/3.

Mehegan, John. [1959] 1984. Jazz Improvisation Vol. 1: Tonal and Rhythmic Principles. Revised and Enlarged Edition. Amsco Music Publications.

Michaelsen, Garrett. 2013. Analyzing Musical Interaction in Jazz Improvisations of the 1960s. PhD diss., Indiana University.

Miller, Ron. 2000. Modal Jazz Composition and Harmony. Rottenburg, Germany: Advance Music. 
Monson, Ingrid. 1997. Sayin' Something: Jazz Improvisation and Interaction. Chicago: University of Chicago Press.

Moten, Fred. 2003. In the Break: The Aesthetics of the Black Radical Tradition. Minneapolis: University of Minnesota Press.

O'Gallagher, John. 2013. Twelve-Tone Improvisation: A Method for Using Tone Rows in Jazz. Advance Music Publishing.

Peñalosa, David. 2010. Rumba Quinto: Lessons in a Musical Art Form. Redway, CA: Bembe Books.

Peters, Gary. 2009. The Philosophy of Improvisation. Chicago: University of Chicago Press.

Rahn, Jay. 1987. "Asymmetrical Ostinatos in Sub-Saharan Music: Time, Pitch, and Cycles Reconsidered.” In Theory Only 9/7 (1987): 23-37.

Rawlins, Robert. 2000. "Review of Mark Levine, The Jazz Theory Book.” Music Theory Online 6/1.

Reeves, Scott. 2006. Creative Jazz Improvisation. Fourth Edition. New York: Pearson.

Rinzler, Paul. 2008. The Contradictions of Jazz. Lanham, MD: Scarecrow Press.

Steinbeck, Paul. 2008. “Analyzing the Music of the Art Ensemble of Chicago.” Dutch Journal of Music Theory 13/1: 56-68.

Stover, Chris. 2012. "Review of Keith Waters, The Studio Recordings of the Miles Davis Quintet: 1965-68.” Music Theory Online 18/1.

. 2013a. "Analysis as Multiplicity." Journal of Music Theory Pedagogy 27, 111140.

. 2013b. "Review-Essay: The Philosophy of Improvisation by Gary Peters." Music Theory Spectrum 35/2, 261-267.

. 2015. "Analysis, Improvisation, and Openness." In Improvisation and Music Education, edited by Ajay Heble and Mark Laver. In process.

Strunk, Steve. 1979. "The Harmony of Early Bop: A Layered Approach.” Journal of Jazz Studies 6: 4-53.

1985. "Bebop Melodic Lines: Tonal Characteristics." Annual Review of Jazz Studies 3: 97-120.

Washburne, Christopher. 1997. "The Clave of Jazz: A Caribbean Contribution to the Rhythmic Foundation of an African-American Music.” Black Music Research Journal 17/1 : 59-80. 
Waters, Keith. 2011. The Studio Recordings of the Miles Davis Quintet: 1965-68. New York and Oxford: Oxford University Press.

Yamaguchi, Masaya. 2011. Lexicon of Geometric Patterns for Jazz Improvisation. Masaya Music Services.

About the Contributor

Chris STOVer is Assistant Professor of Music Theory and Composition at The New School. His recent publications appear in Analytic Approaches to World Music, Music Theory Spectrum, The Open Space Magazine, Journal of Music Theory Pedagogy, and the edited volumes Improvisation and Music Education and Sounds of Resistance. He is also a busy trombonist and composer in New York City.

The Journal of Jazz Studies (JJS) is published by the Institute of Jazz Studies at the Newark campus of Rutgers, The State University of New Jersey. JJS is hosted online by the Rutgers University Libraries at http://jjs.libraries.rutgers.edu. 